\title{
A Economia numa
}

\section{Perspectiva Interdisciplinar 3}

Elói Martins Senhoras

(Organizador)
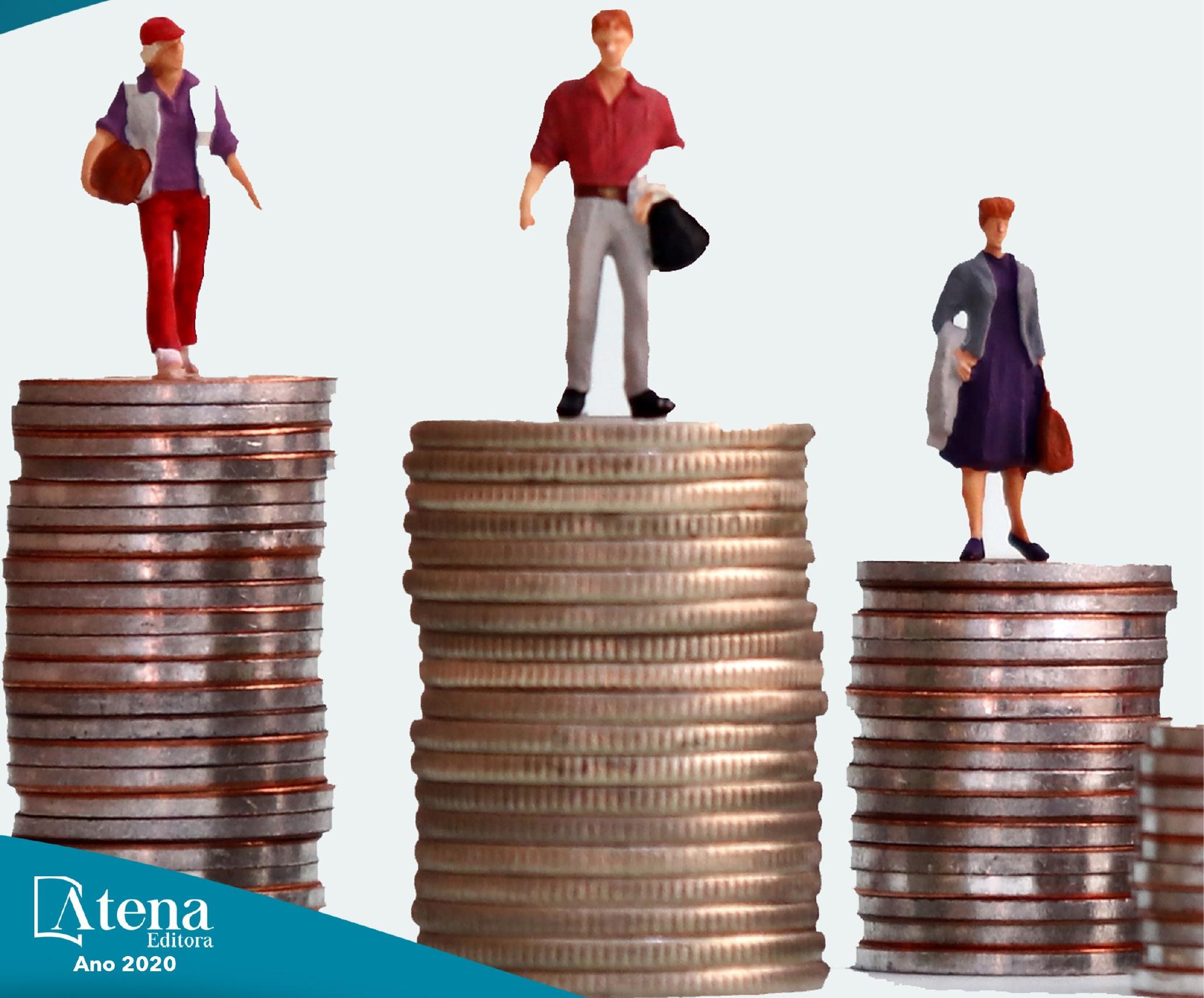


\section{A Economia numa}

\section{Perspectiva Interdisciplinar 3}

Elói Martins Senhoras

(Organizador)
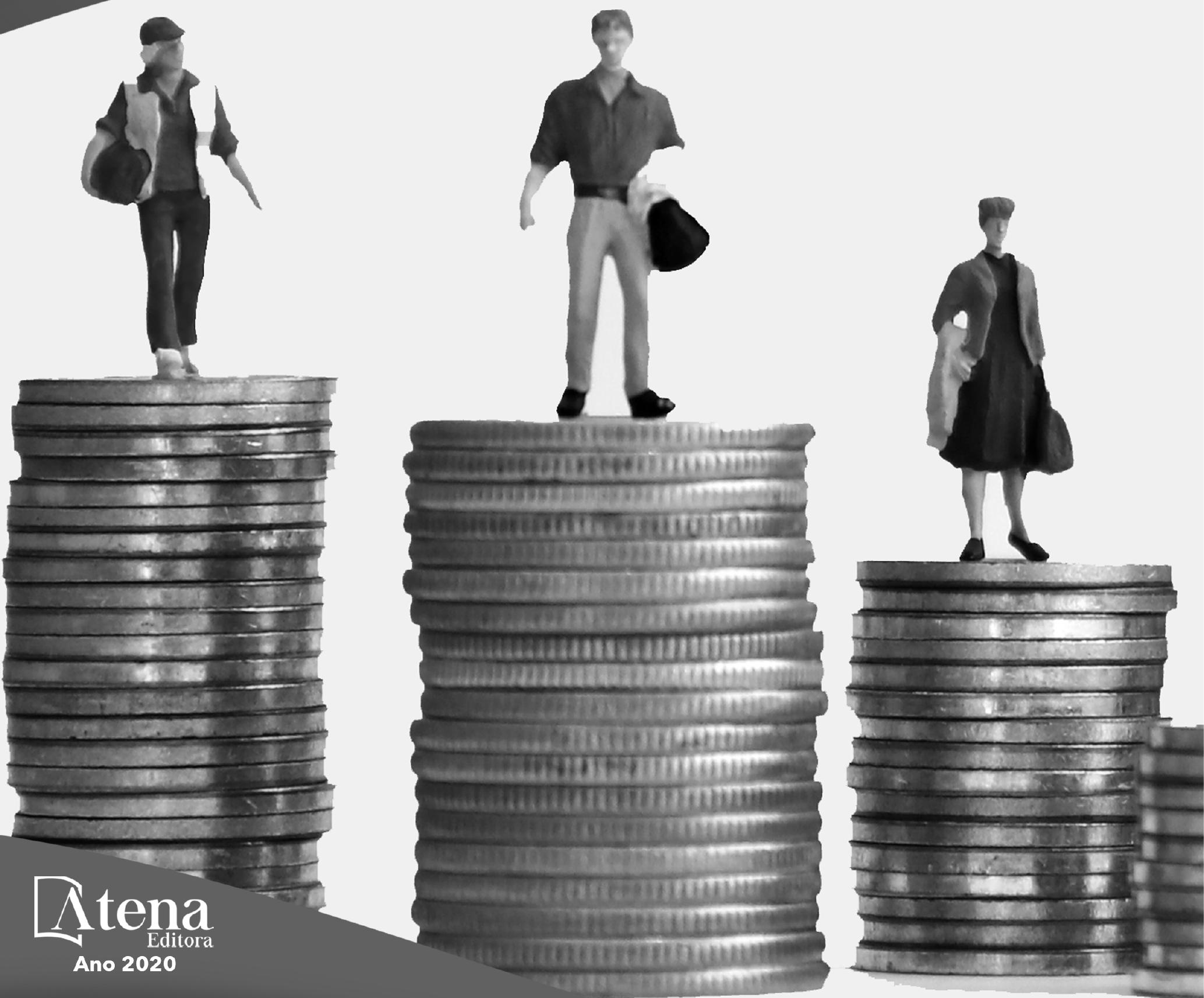


\author{
2020 by Atena Editora \\ Copyright (C) Atena Editora \\ Copyright do Texto (C) 2020 Os autores \\ Copyright da Edição (c) 2020 Atena Editora \\ Editora Chefe: Prof ${ }^{\mathrm{a}} \mathrm{Dr}^{\mathrm{a}}$ Antonella Carvalho de Oliveira \\ Diagramação: Natália Sandrini de Azevedo \\ Edição de Arte: Lorena Prestes \\ Revisão: Os Autores
}

cc) (1) Todo o conteúdo deste livro está licenciado sob uma Licença de Atribuição Creative

Commons. Atribuição 4.0 Internacional (CC BY 4.0).

O conteúdo dos artigos e seus dados em sua forma, correção e confiabilidade são de responsabilidade exclusiva dos autores. Permitido o download da obra e o compartilhamento desde que sejam atribuídos créditos aos autores, mas sem a possibilidade de alterá-la de nenhuma forma ou utilizá-la para fins comerciais.

\title{
Conselho Editorial
}

\section{Ciências Humanas e Sociais Aplicadas}

Prof $^{a}$ Dr $^{\text {a }}$ Adriana Demite Stephani - Universidade Federal do Tocantins

Prof. Dr. Álvaro Augusto de Borba Barreto - Universidade Federal de Pelotas

Prof. Dr. Alexandre Jose Schumacher - Instituto Federal de Educação, Ciência e Tecnologia de Mato Grosso

Prof $^{a} \mathrm{Dr}^{\mathrm{a}}$ Angeli Rose do Nascimento - Universidade Federal do Estado do Rio de Janeiro

Prof. Dr. Antonio Carlos Frasson - Universidade Tecnológica Federal do Paraná

Prof. Dr. Antonio Gasparetto Júnior - Instituto Federal do Sudeste de Minas Gerais

Prof. Dr. Antonio Isidro-Filho - Universidade de Brasília

Prof. Dr. Carlos Antonio de Souza Moraes - Universidade Federal Fluminense

Prof $^{a} \operatorname{Dr}^{\mathrm{a}}$ Cristina Gaio - Universidade de Lisboa

Prof $^{a}$ Dr $^{\text {a }}$ Denise Rocha - Universidade Federal do Ceará

Prof. Dr. Deyvison de Lima Oliveira - Universidade Federal de Rondônia

Prof. Dr. Edvaldo Antunes de Farias - Universidade Estácio de Sá

Prof. Dr. Eloi Martins Senhora - Universidade Federal de Roraima

Prof. Dr. Fabiano Tadeu Grazioli - Universidade Regional Integrada do Alto Uruguai e das Missões

Prof. Dr. Gilmei Fleck - Universidade Estadual do Oeste do Paraná

Prof. Dr. Gustavo Henrique Cepolini Ferreira - Universidade Estadual de Montes Claros

Prof $^{\mathrm{a}} \mathrm{Dr}^{\mathrm{a}}$ Ivone Goulart Lopes - Istituto Internazionele delle Figlie de Maria Ausiliatrice

Prof. Dr. Julio Candido de Meirelles Junior - Universidade Federal Fluminense

Prof $^{a}$ Dr $^{a}$ Keyla Christina Almeida Portela - Instituto Federal de Educação, Ciência e Tecnologia de Mato Grosso

Prof $^{\mathrm{a}} \mathrm{Dr}^{\mathrm{a}}$ Lina Maria Gonçalves - Universidade Federal do Tocantins

Prof. Dr. Luis Ricardo Fernando da Costa - Universidade Estadual de Montes Claros

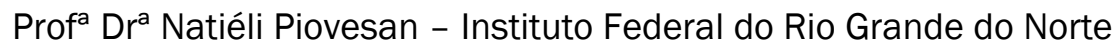

Prof. Dr. Marcelo Pereira da Silva - Universidade Federal do Maranhão

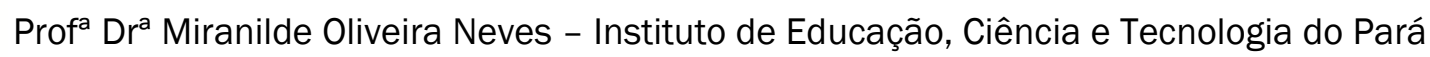

Prof $^{a}$ Dr $^{\text {a }}$ Paola Andressa Scortegagna - Universidade Estadual de Ponta Grossa

Prof $^{a}{ }^{D r}{ }^{a}$ Rita de Cássia da Silva Oliveira - Universidade Estadual de Ponta Grossa

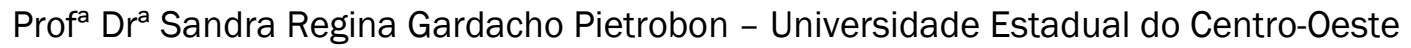

Prof $^{a}$ Dr $^{\text {a }}$ Sheila Marta Carregosa Rocha - Universidade do Estado da Bahia

Prof. Dr. Rui Maia Diamantino - Universidade Salvador

Prof. Dr. Urandi João Rodrigues Junior - Universidade Federal do Oeste do Pará

Prof $^{a}$ Dr $^{a}$ Vanessa Bordin Viera - Universidade Federal de Campina Grande

\section{Qtena}


Prof. Dr. William Cleber Domingues Silva - Universidade Federal Rural do Rio de Janeiro

Prof. Dr. Willian Douglas Guilherme - Universidade Federal do Tocantins

\section{Ciências Agrárias e Multidisciplinar}

Prof. Dr. Alexandre Igor Azevedo Pereira - Instituto Federal Goiano

Prof. Dr. Antonio Pasqualetto - Pontifícia Universidade Católica de Goiás

Prof. Dr. Cleberton Correia Santos - Universidade Federal da Grande Dourados

Prof $^{\mathrm{a}} \mathrm{Dr}^{\mathrm{a}}$ Daiane Garabeli Trojan - Universidade Norte do Paraná

Prof $^{a}$ Dra $^{a}$ Diocléa Almeida Seabra Silva - Universidade Federal Rural da Amazônia

Prof. Dr. Écio Souza Diniz - Universidade Federal de Viçosa

Prof. Dr. Fábio Steiner - Universidade Estadual de Mato Grosso do Sul

Prof. Dr. Fágner Cavalcante Patrocínio dos Santos - Universidade Federal do Ceará

Prof $^{a}$ Dr $^{a}$ Girlene Santos de Souza - Universidade Federal do Recôncavo da Bahia

Prof. Dr. Júlio César Ribeiro - Universidade Federal Rural do Rio de Janeiro

Prof $^{a}$ Dr $^{a}$ Lina Raquel Santos Araújo - Universidade Estadual do Ceará

Prof. Dr. Pedro Manuel Villa - Universidade Federal de Viçosa

Prof $^{a}$ Dr $^{\mathrm{a}}$ Raissa Rachel Salustriano da Silva Matos - Universidade Federal do Maranhão

Prof. Dr. Ronilson Freitas de Souza - Universidade do Estado do Pará

Prof $^{a}$ Dr $^{a}$ Talita de Santos Matos - Universidade Federal Rural do Rio de Janeiro

Prof. Dr. Tiago da Silva Teófilo - Universidade Federal Rural do Semi-Árido

Prof. Dr. Valdemar Antonio Paffaro Junior - Universidade Federal de Alfenas

\section{Ciências Biológicas e da Saúde}

Prof. Dr. André Ribeiro da Silva - Universidade de Brasília

Prof $^{\mathrm{a}} \mathrm{Dr}^{\mathrm{a}}$ Anelise Levay Murari - Universidade Federal de Pelotas

Prof. Dr. Benedito Rodrigues da Silva Neto - Universidade Federal de Goiás

Prof. Dr. Edson da Silva - Universidade Federal dos Vales do Jequitinhonha e Mucuri

Prof $^{a}$ Dr $^{a}$ Eleuza Rodrigues Machado - Faculdade Anhanguera de Brasília

Prof $^{a}$ Dr $^{a}$ Elane Schwinden Prudêncio - Universidade Federal de Santa Catarina

Prof $^{a}$ Dr $^{a}$ Eysler Gonçalves Maia Brasil - Universidade da Integração Internacional da Lusofonia Afro-Brasileira

Prof. Dr. Ferlando Lima Santos - Universidade Federal do Recôncavo da Bahia

Prof. Dr. Fernando José Guedes da Silva Júnior - Universidade Federal do Piauí

Prof $^{\mathrm{a}} \mathrm{Dr}^{\mathrm{a}}$ Gabriela Vieira do Amaral - Universidade de Vassouras

Prof. Dr. Gianfábio Pimentel Franco - Universidade Federal de Santa Maria

Prof $^{a}$ Dr $^{\mathrm{a}}$ Iara Lúcia Tescarollo - Universidade São Francisco

Prof. Dr. Igor Luiz Vieira de Lima Santos - Universidade Federal de Campina Grande

Prof. Dr. José Max Barbosa de Oliveira Junior - Universidade Federal do Oeste do Pará

Prof. Dr. Luís Paulo Souza e Souza - Universidade Federal do Amazonas

Prof $^{a}$ Dr$^{a}$ Magnólia de Araújo Campos - Universidade Federal de Campina Grande

Prof. Dr. Marcus Fernando da Silva Praxedes - Universidade Federal do Recôncavo da Bahia

Prof $^{a}$ Dr $^{a}$ Mylena Andréa Oliveira Torres - Universidade Ceuma

Prof $^{\mathrm{a}} \mathrm{Dr}^{\mathrm{a}}$ Natiéli Piovesan - Instituto Federacl do Rio Grande do Norte

Prof. Dr. Paulo Inada - Universidade Estadual de Maringá

Prof $^{a}{ }^{\text {Dr }}{ }^{\mathrm{a}}$ Renata Mendes de Freitas - Universidade Federal de Juiz de Fora

Prof $^{a}$ Dr $^{a}$ Vanessa Lima Gonçalves - Universidade Estadual de Ponta Grossa

Prof $^{a}$ Dr $^{\mathrm{a}}$ Vanessa Bordin Viera - Universidade Federal de Campina Grande

\section{Ciências Exatas e da Terra e Engenharias}

Prof. Dr. Adélio Alcino Sampaio Castro Machado - Universidade do Porto 
Prof. Dr. Alexandre Leite dos Santos Silva - Universidade Federal do Piauí

Prof. Dr. Carlos Eduardo Sanches de Andrade - Universidade Federal de Goiás

Prof $^{a}$ Dr $^{a}$ Carmen Lúcia Voigt - Universidade Norte do Paraná

Prof. Dr. Eloi Rufato Junior - Universidade Tecnológica Federal do Paraná

Prof. Dr. Fabrício Menezes Ramos - Instituto Federal do Pará

Prof. Dr. Juliano Carlo Rufino de Freitas - Universidade Federal de Campina Grande

Prof $^{\mathrm{a}} \mathrm{Dr}^{\mathrm{a}}$ Luciana do Nascimento Mendes - Instituto Federal de Educação, Ciência e Tecnologia do Rio Grande do Norte

Prof. Dr. Marcelo Marques - Universidade Estadual de Maringá

Prof ${ }^{a}$ Dr $^{a}$ Neiva Maria de Almeida - Universidade Federal da Paraíba

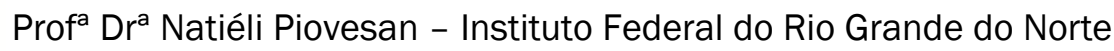

Prof. Dr. Takeshy Tachizawa - Faculdade de Campo Limpo Paulista

\section{Conselho Técnico Científico}

Prof. Me. Abrãao Carvalho Nogueira - Universidade Federal do Espírito Santo

Prof. Me. Adalberto Zorzo - Centro Estadual de Educação Tecnológica Paula Souza

Prof. Me. Adalto Moreira Braz - Universidade Federal de Goiás

Prof. Dr. Adaylson Wagner Sousa de Vasconcelos - Ordem dos Advogados do Brasil/Seccional Paraíba

Prof. Me. André Flávio Gonçalves Silva - Universidade Federal do Maranhão

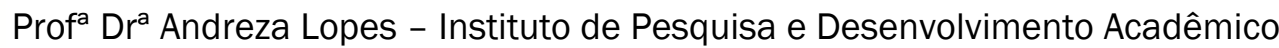

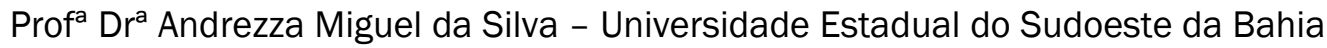

Prof. Dr. Antonio Hot Pereira de Faria - Polícia Militar de Minas Gerais

Prof $^{a}$ Ma. Bianca Camargo Martins - UniCesumar

Prof $^{a}$ Ma. Carolina Shimomura Nanya - Universidade Federal de São Carlos

Prof. Me. Carlos Antônio dos Santos - Universidade Federal Rural do Rio de Janeiro

Prof. Ma. Cláudia de Araújo Marques - Faculdade de Música do Espírito Santo

Prof $^{a}$ Dr $^{a}$ Cláudia Taís Siqueira Cagliari - Centro Universitário Dinâmica das Cataratas

Prof. Me. Daniel da Silva Miranda - Universidade Federal do Pará

Prof ${ }^{a}$ Ma. Daniela da Silva Rodrigues - Universidade de Brasília

Prof ${ }^{\mathrm{a}}$ Ma. Dayane de Melo Barros - Universidade Federal de Pernambuco

Prof. Me. Douglas Santos Mezacas - Universidade Estadual de Goiás

Prof. Dr. Edwaldo Costa - Marinha do Brasil

Prof. Me. Eduardo Gomes de Oliveira - Faculdades Unificadas Doctum de Cataguases

Prof. Me. Eliel Constantino da Silva - Universidade Estadual Paulista Júlio de Mesquita

Prof. Me. Euvaldo de Sousa Costa Junior - Prefeitura Municipal de São João do Piauí

Prof ${ }^{a}$ Ma. Fabiana Coelho Couto Rocha Corrêa - Centro Universitário Estácio Juiz de Fora

Prof. Dr. Fabiano Lemos Pereira - Prefeitura Municipal de Macaé

Prof. Me. Felipe da Costa Negrão - Universidade Federal do Amazonas

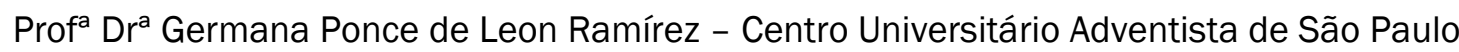

Prof. Me. Gevair Campos - Instituto Mineiro de Agropecuária

Prof. Dr. Guilherme Renato Gomes - Universidade Norte do Paraná

Prof. Me. Gustavo Krahl - Universidade do Oeste de Santa Catarina

Prof. Me. Helton Rangel Coutinho Junior - Tribunal de Justiça do Estado do Rio de Janeiro

Prof $^{a}$ Ma. Jaqueline Oliveira Rezende - Universidade Federal de Uberlândia

Prof. Me. Javier Antonio Albornoz - University of Miami and Miami Dade College

Prof $^{a}$ Ma. Jéssica Verger Nardeli - Universidade Estadual Paulista Júlio de Mesquita Filho

Prof. Me. Jhonatan da Silva Lima - Universidade Federal do Pará

Prof. Me. José Luiz Leonardo de Araujo Pimenta - Instituto Nacional de Investigación Agropecuaria Uruguay

Prof. Me. José Messias Ribeiro Júnior - Instituto Federal de Educação Tecnológica de Pernambuco 
Prof $^{a}$ Ma. Juliana Thaisa Rodrigues Pacheco - Universidade Estadual de Ponta Grossa

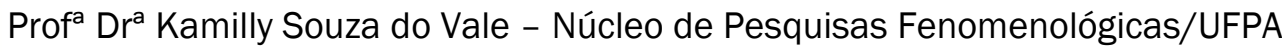

Prof $^{a}$ Dr $^{a}$ Karina de Araújo Dias - Prefeitura Municipal de Florianópolis

Prof. Dr. Lázaro Castro Silva Nascimento - Laboratório de Fenomenologia \& Subjetividade/UFPR

Prof. Me. Leonardo Tullio - Universidade Estadual de Ponta Grossa

Prof $^{a}$ Ma. Lilian Coelho de Freitas - Instituto Federal do Pará

Prof ${ }^{a}$ Ma. Liliani Aparecida Sereno Fontes de Medeiros - Consórcio CEDERJ

Prof $^{a}$ Dr $^{a}$ Lívia do Carmo Silva - Universidade Federal de Goiás

Prof. Me. Lucio Marques Vieira Souza - Secretaria de Estado da Educação, do Esporte e da Cultura de Sergipe Prof. Me. Luis Henrique Almeida Castro - Universidade Federal da Grande Dourados

Prof. Dr. Luan Vinicius Bernardelli - Universidade Estadual do Paraná

Prof. Dr. Michel da Costa - Universidade Metropolitana de Santos

Prof. Dr. Marcelo Máximo Purificação - Fundação Integrada Municipal de Ensino Superior

Prof. Me. Marcos Aurelio Alves e Silva - Instituto Federal de Educação, Ciência e Tecnologia de São Paulo

Prof $^{a}$ Ma. Marileila Marques Toledo - Universidade Federal dos Vales do Jequitinhonha e Mucuri

Prof. Me. Ricardo Sérgio da Silva - Universidade Federal de Pernambuco

Prof. Me. Rafael Henrique Silva - Hospital Universitário da Universidade Federal da Grande Dourados

Prof ${ }^{a}$ Ma. Renata Luciane Polsaque Young Blood - UniSecal

Prof $^{a}$ Ma. Solange Aparecida de Souza Monteiro - Instituto Federal de São Paulo

Prof. Me. Tallys Newton Fernandes de Matos - Faculdade Regional Jaguaribana

Prof. Dr. Welleson Feitosa Gazel - Universidade Paulista

\begin{tabular}{|c|}
\hline $\begin{array}{c}\text { Dados Internacionais de Catalogação na Publicação (CIP) } \\
\text { (eDOC BRASIL, Belo Horizonte/MG) }\end{array}$ \\
\hline E19 A economia numa perspectiva interdisciplinar 3 [recurso eletrônico] / \\
Organizador Elói Martins Senhoras. - Ponta Grossa, PR: Atena, \\
2020. \\
Formato: PDF \\
Requisitos de sistema: Adobe Acrobat Reader \\
Modo de acesso: World Wide Web \\
Inclui bibliografia \\
ISBN 978-65-5706-105-3 \\
DOI 10.22533/at.ed.053201506 \\
1. Abordagem interdisciplinar do conhecimento. 2. Economia - \\
Pesquisa - Brasil. I. Senhoras, Elói Martins. \\
Elaborado por Maurício Amormino Júnior - CRB6/2422 \\
\hline
\end{tabular}

Atena Editora

Ponta Grossa - Paraná - Brasil

www.atenaeditora.com.br

contato@atenaeditora.com.br 


\section{APRESENTAÇÃO}

O campo científico da Economia surge como um dos grandes expoentes da emergência do movimento lluminista no século XVIII e desde então tem passado por diferentes revoluções e movimentos epistêmicos que procuraram, tanto, fomentar uma construção científica autônoma, quanto, engendrar interações com outros campos do pensamento humano.

Tomando como referência uma abordagem absorvente e relacional, o presente livro, "A Economia numa Perspectiva Interdisciplinar 3", vem corroborar com o campo epistemológico de Economia no Brasil e em Portugal a partir de uma agenda de estudos que se fundamenta na pluralidade de vozes e discursos.

Resultado de trabalho coletivo de diferentes pesquisadoras e pesquisadores portugueses e brasileiros, oriundos das macrorregiões Sul, Sudeste e Norte, este livro traz uma rica pluralidade de debates e análises que fortalecem a compreensão interdisciplinar existente no campo epistemológico da Economia.

Organizado em treze capítulos, as pesquisas presentes nesta obra foram estruturadas com base em um convergente método dedutivo, no qual partiu-se de marcos de abstração de modelos, teorias e análises históricas até se chegar à análise empírica específica da realidade concreta e dos respectivos objetos de estudo.

A natureza exploratória, descritiva e explicativas dos capítulos caracterizou-se por uma abordagem quali-quantitativa que partiu dos procedimentos de revisão bibliográfica e documental no levantamento de dados, combinada ao uso de técnicas de hermenêutica e modelagem econômica, bem como análise gráfica e geoespacial na interpretação dos dados.

$\mathrm{Na}$ construção interdisciplinar do conhecimento, comandada pelo olhar econômico, cinco eixos temáticos se destacaram, permitindo aglutinar as análises e discussões dos treze capítulos, por meio de recortes teóricos relacionados aos ramos da Economia Solidária, Economia do Trabalho, Economia Urbana e Industrial, Economia Organizacional e Economia Monetária e Financeira.

Com base nas análises e discussões apresentadas nesta presente obra, composta por treze capítulos e cinco ramos teóricos, subsídios são apresentados para uma apreensão interdisciplinar do campo científico de Economia findando explorar à luz de um olhar descritivo e prescritivo a complexa realidade em suas interações no dinâmico tripé Homem-Mercado-Estado.

Em nome do grupo diversificado de profissionais envolvidos neste livro e comprometidos com o avanço do campo científico de Economia, convidamos você leitor(a) a desbravar tradicionais e novas reflexões à luz de uma abordagem interdisciplinar que valoriza o diálogo e a pluralidade na abordagem de nossa complexa realidade empírica, rica de desafios para o pensamento e a reflexão.

Excelente leitura! 


\section{SUMÁRIO}

CAPÍTULO 1

O PAPEL DA ECONOMIA SOLIDÁRIA PARA O DESENVOLVIMENTO COMUNITÁRIO

Reinaldo Eduardo da Silva Sales

Mayara Mendes Leal

DOI 10.22533/at.ed.0532015061

CAPÍTULO 2 17

EMPREENDIMENTO ECONÔMICO SOLIDÁRIO: SATISFAÇÃO DOS ASSOCIADOS E MELHORIA DAS CONDIÇÕES SOCIOECONÔMICAS DO PRODUTOR RURAL

Madson Igor Pereira Portal

Lailson da Silva Freitas

Marta Laura Noronha da Silva Gonçalves

Janusa Mérlem dos Santos Lopes

Gabriel Lélis Pereira da Silva

Marzane Pinto de Souza

Mario Miguel Amin Garcia Hereros

Félix Lélis da Silva

DOI 10.22533/at.ed.0532015062

CAPÍTULO 3 38

AGROECOLOGIA, EDUCAÇÃO E SOCIEDADE: OS PASSOS DE UMA EXPERIÊNCIA DE ECONOMIA SOLIDÁRIA CAMPESINA

Ariane Domborovski

Bruno Henrique Fujarra

DOI 10.22533/at.ed.0532015063

CAPÍTULO 4 49

OS DESAFIOS PARA AS MULHERES NO MERCADO DE TRABALHO: UMA PRESPECTIVA FRETE À REVOLUÇÂO INDUSTRIAL 4.0

Samanda Silva da Rosa

DOI 10.22533/at.ed.0532015064

CAPÍTULO 5 62

ABERTURA ECONÔMICA E DISCRIMINAÇÃO SALARIAL POR SEXO E RAÇA: UM ESTUDO PARA A ECONOMIA PARANAENSE

Júlio Vicente Cateia

Paulo Ricardo Feistel

DOI 10.22533/at.ed.0532015065

CAPÍTULO 6 86

ANÁLISE DOS INDICADORES REGIONAIS DE LOCALIZAÇÃO E ESPECIALIZAÇÃO PARA A MICRORREGIÃO DE TOLEDO-PR

Giovanna da Silva Cassanelli

Lucir Reinaldo Alves

Jandir Ferrera de Lima

Moacir Piffer

DOI 10.22533/at.ed.0532015066 
ANÁLISE DE MERCADO DO SETOR INDUSTRIAL DO MUNICÍPIO DE TOLEDO-PR UTILIZANDO ANÁLISE DE CORRESPONDÊNCIAS MÚLTIPLAS

Lucir Reinaldo Alves

Eduarda Pires Valente da Silva Marques da Costa

Nuno Manuel Sessarego Marques da Costa

DOI 10.22533/at.ed.0532015067

CAPÍTULO 8 130

COMPARAÇÃO DAS MARGENS ECONÔMICAS ENTRE A PRODUÇÃO TOTAL DE LEITE ORGÂNICA E CONVENCIONAL USANDO BENCHMARKING

Thérèsse Camille Nascimento Holmström

Elisa Cristina Modesto

DOI 10.22533/at.ed.0532015068

CAPÍTULO 9 140

A IMPORTÂNCIA DA LIDERANÇA MOTIVADORA PARA A MELHORIA DOS RESULTADOS ORGANIZACIONAIS

Samanda Silva da Rosa

DOI 10.22533/at.ed.0532015069

CAPÍTULO 10 149

O CARÁTER ECONÔMICO DO CONHECIMENTO NA SOCIEDADE ATUAL

Adelcio Machado dos Santos

Alexandre Carvalho Acosta

Liz Barbara Borghetti

DOI 10.22533/at.ed.05320150610

CAPÍTULO 11 162

HELICOPTER MONEY EM TEMPO DE COVID19: UMA PROPOSTA PARA A MUTUALIZAÇÃO DO ESFORÇO FINANCEIRO EM PORTUGAL

Diamantino Ribeiro

João Filipe Monteiro Ribeiro

DOI 10.22533/at.ed.05320150611

CAPÍTULO 12 177

MOBILIZANDO O CONCEITO DE HEGEMONIA PARA O CONTEXTO FINANCEIRIZADO BRASILEIRO

Rodolfo Palazzo Dias

DOI 10.22533/at.ed.05320150612

CAPÍTULO 13

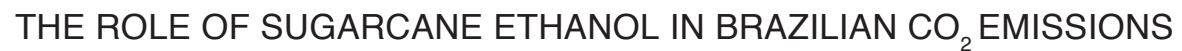

Guilherme Barbosa Fernandes

DOI 10.22533/at.ed.05320150613

SOBRE O ORGANIZADOR 203

ÍNDICE REMISSIVO 


\section{ANÁLISE DE MERCADO DO SETOR INDUSTRIAL DO MUNICÍPIO DE TOLEDO-PR UTILIZANDO ANÁLISE DE CORRESPONDÊNCIAS MÚLTIPLAS}

Data de aceite: 01/06/2020

Data de submissão: 29/04/2020

Lucir Reinaldo Alves Universidade Estadual do Oeste do Paraná (UNIOESTE/Campus Toledo), Curso de Ciências Econômicas e Programa de PósGraduação em Desenvolvimento Regional e Agronegócio (PGDRA). Grupo de Pesquisas em Desenvolvimento Regional e Agronegócio

(GEPEC), Grupo de Pesquisa Modelação, Ordenamento e Planejamento Territorial (MOPT) e Núcleo de Desenvolvimento Regional (NDR). Toledo - Paraná - Brasil ORCID: https://orcid.org/0000-0001-5703-623X

E-mails: lucir_a@hotmail.com e lucir.alves@ unioeste.br

\section{Eduarda Pires Valente da Silva Marques da}

Costa

Universidade de Lisboa. Instituto de Geografia e Ordenamento do Território (IGOT). Centro de Estudos Geográficos (CEG). Grupo de Pesquisa

Modelação, Ordenamento e Planejamento Territorial (MOPT).

Lisboa - Portugal ORCID: https://orcid.org/0000-0001-5070-3562 E-mail: eduarda.costa@campus.ul.pt
Nuno Manuel Sessarego Marques da Costa Universidade de Lisboa. Instituto de Geografia e Ordenamento do Território (IGOT). Centro de Estudos Geográficos (CEG). Grupo de Pesquisa Modelação, Ordenamento e Planejamento Territorial (MOPT).

Lisboa - Portugal

ORCID: https://orcid.org/0000-0003-4859-9668

E-mail: nunocosta@campus.ul.pt

RESUMO: Este trabalho analisa o mercado de atuação das empresas industriais do município de Toledo-PR em suas diversas características. Utilizou-se dados secundários diversos além de uma Análise de Correspondências Múltiplas com dados primários coletados em 2014 para caracterizar o setor industrial. Os resultados mostraram que o setor industrial possui um papel importante na dinâmica econômica municipal se consolidando no subsetor de baixa tecnologia, e têm apresentado um crescimento expressivo no subsetor de alta tecnologia, mostrando sinais de uma reestruturação produtiva em desenvolvimento. $\mathrm{O}$ setor industrial é composto por grandes empresas que não possuem uma relação direta com a produção de matériasprimas existente no município, reforçando o fato do município ter que incentivar essas produções de forma regional para poder consolidar o seu 
processo de desenvolvimento.

PALAVRAS-CHAVE: Análise de Correspondência Múltipla, Mercado, Município de ToledoPR, Setor Industrial.

\title{
A MARKET ANALYSIS OF TOLEDO-PR CITY INDUSTRIAL SECTOR USING MULTIPLE CORRESPONDENCE ANALYSIS
}

\begin{abstract}
This paper analyzes the market performance of industrial enterprises in the city of Toledo-PR in its various features. Several secondary data were used in addition to a Multiple Correspondence Analysis with primary data collected in 2014 to characterize the industrial sector. The results showed that the industrial sector has an important role in the municipal economic dynamics, consolidating in the low technology subsector, and have shown a significant growth in the high technology subsector, showing signs of a productive restructuring in development. The industrial sector is composed of large companies that do not have a direct relation with the production of raw materials existing in the municipality, reinforcing the fact that the municipality has to encourage these productions in a regional way in order to consolidate its development process.
\end{abstract}

KEYWORDS: Multiple Correspondence Analysis, Market, City of Toledo-PR, Industrial Sector.

\section{I INTRODUÇÃO}

A metodologia de análises fatoriais, conforme ressalta Gonçalves JUNIOR. et al. (2011) e Costa, Dentinho \& Nijkamp (2011), é uma técnica estatística multivariada muito utilizada no meio acadêmico, que objetiva estabelecer relações de interdependência entre variáveis distintas. Este tipo de análise é capaz de identificar dimensões de variabilidade comuns existentes em um conjunto de dados, ou seja, descreve um conjunto de variáveis originais através da criação de um número menor de dimensões, ou fatores. Esses fatores são resultados do relacionamento linear entre as variáveis e que possuem a capacidade de explicação de uma parcela de variação das variáveis originais. Assim, a análise fatorial é capaz de agrupar variáveis observáveis em um fator (ou fatores) não diretamente observáveis.

No geral, a análise fatorial utiliza dados quantitativos em sua análise. Por outro lado, a Análise de Correspondências Múltiplas (ACM) possui uma justificativa técnica semelhante para a sua utilização, pois também reduz as informações em dimensões/fatores. A principal diferença se dá pelo fato deste tipo de análise privilegiar dados qualitativos na sua origem, em vez de quantitativos.

O uso de informações qualitativas é muito comum nas ciências sociais aplicadas. Parte-se do princípio de que os indivíduos possuem múltiplas propriedades em relação à posição social, econômica, cultural, política, bem como às suas características pessoais 
tais como o sexo, a idade ou o estado civil. Estas propriedades possuem valores e efeitos próprios de si e são analiticamente irredutíveis. Por isso, perceber as diversas relações que se estabelecem entre todas essas propriedades é uma forma de se encontrar, a partir de uma análise relacional dos múltiplos indicadores, os perfis comuns dos indivíduos. Exemplos são os perfis de consumo, estilos de vida, segmentos de mercado, entre outros muitos, identificando-se, assim, grupos de indivíduos (pessoas, empresas, setores de atividade, regiões, etc.) que, coexistindo no mesmo espaço, partilham sistemas distintos de práticas, estilos, atitudes, representações, culturas.

É neste contexto que o objetivo deste trabalho é, utilizando como elemento de pesquisa o município de Toledo-PR, analisar o mercado de atuação das empresas industriais em suas diversas características. Este município está localizado no Oeste do Estado do Paraná, no Sul do Brasil, e tem passado por diversas transformações econômicas a partir dos anos 2000. Até o final do século XX a estrutura produtiva deste município era considerada relacionada ao agronegócio. Apesar de ainda se destacar no contexto econômico regional pela participação expressiva na produção do setor primário do Estado, e também no contexto nacional, pela participação na indústria da transformação, principalmente de produção agroalimentar, novos subsetores considerados de alta tecnologia e conhecimento tem apresentado aumento de sua participação produtiva regional e contribuíram para o crescimento e diversificação industrial.

Desta forma, pretende-se verificar se esta reestruturação está associada a uma melhoria da internacionalização dos mercados de oferta dos seus produtos destas empresas e, ao mesmo tempo, se a aquisição das matérias-primas ocorre regionalmente, o que tende a ter efeitos positivos mais amplos do que quando se adquire externamente à região. Com isso, tem-se uma análise mais ampla do perfil das empresas locais e sua capacidade de influenciar o desenvolvimento do município.

\section{I ELEMENTOS METODOLÓGICOS: A ANÁLISE DE CORRESPONDÊNCIAS MÚLTIPLAS (ACM)}

O procedimento relacionado à Análise de Correspondências Múltiplas (ACM), que também pode ser encontrado como sendo análise de homogeneidade, foi obtido a partir da síntese elaborada por Carvalho (2008). Nesta sessão será efetuada somente uma descrição resumida para clarear como se utilizou este método e se perceber minimamente os procedimentos associados. Um maior detalhamento, com exemplos diversos, é apresentado pela autora, Carvalho (2008), com grande exaustão. Operacionalizou-se a ACM no software SPSS (Statistical Package for the Social Sciences), na versão 17.1 do programa, que é um software de estatísticas de grande difusão, tanto no mundo acadêmico, como no mundo empresarial. 
Utilizou-se dos resultados de uma pesquisa de campo efetuada com 115 empresas do município de Toledo-PR (Figura 1), dos mais diversos setores e atividades econômicas.

Efetuou-se uma amostra levando em consideração o número de empresas que eram associadas à Associação Comercial e Industrial de Toledo (ACIT) devido à parceria que foi efetuada com esta instituição para a realização da pesquisa. Da mesma forma, houve a preocupação de não inquirir mais do que um estabelecimento da mesma empresa e, por isso, a partir deste momento será utilizado o nome "empresa" nas análises para se referir aos resultados dos inquéritos. Vale lembrar que em 2014 havia aproximadamente 2.700 empresas associadas à ACIT e destas foram inquiridas 115 empresas dos setores industrial e de comércio/serviços, entre os meses de maio a agosto de 2014 (com margem de confiança de $90 \%$ e margem de erro de 7,53\%). Um maior detalhamento sobre os inquéritos e seus resultados podem ser encontrados em Alves (2016).

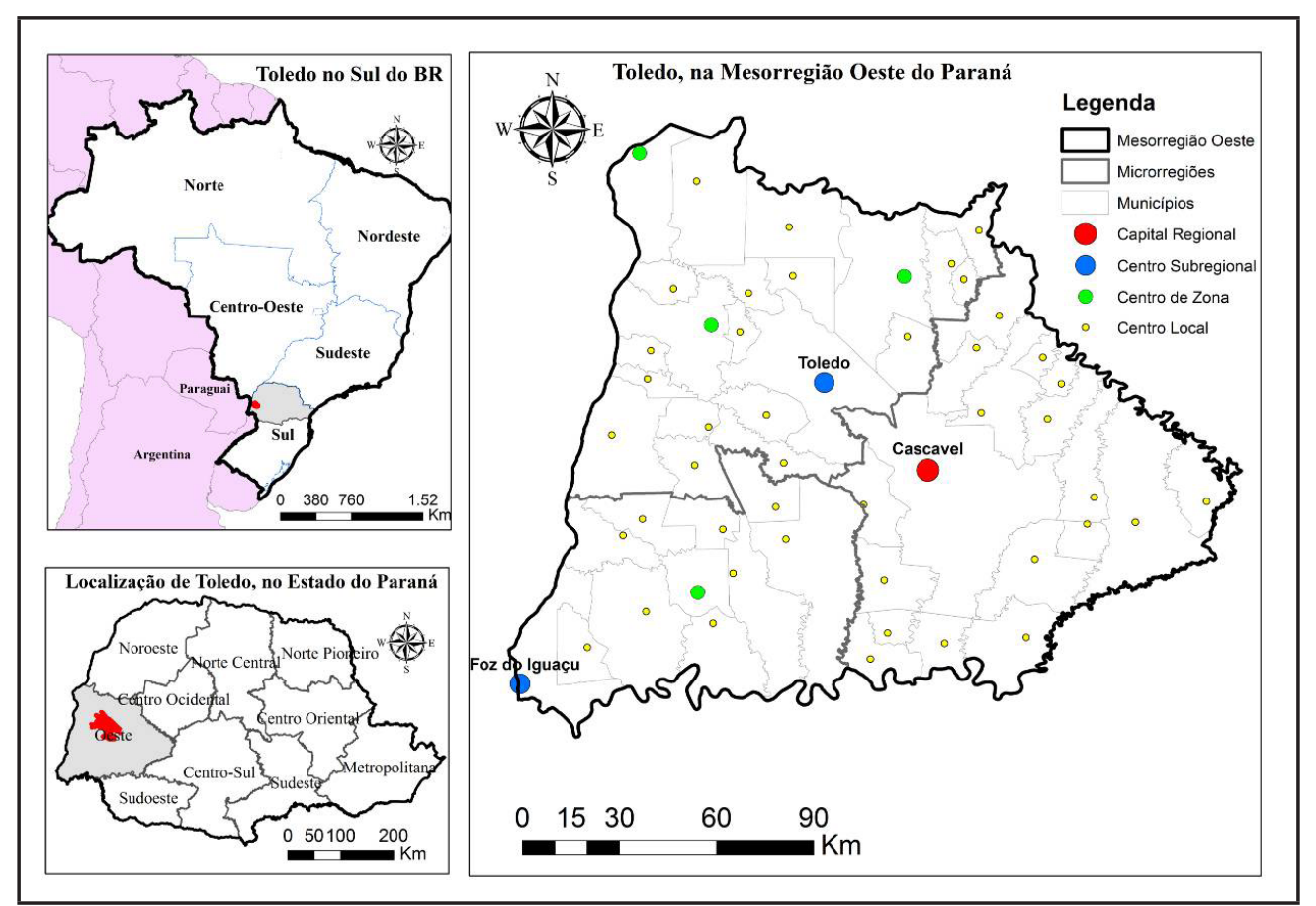

Figura 1 - Localização do município de Toledo-PR Fonte: Elaboração do autor a partir de IBGE (2017).

Conforme já mencionado, a ACM é apropriada aos estudos que ao mesmo tempo utilizam de múltiplos indicadores e que tratam de variáveis qualitativas, especialmente as categorizadas. A partir desta análise é possível realizar e interpretar análises multivariadas para se verificar as múltiplas associações que se estabelecem entre elas num contexto de interdependência.

Esses aspetos mostram a existência de uma multidimensionalidade de situações com que se precisa trabalhar, traduzidos em variáveis, que representam uma análise estrutural do fenômeno a ser estudado. A multidimensionalidade e as análises estruturais dessa multidimensionalidade são dois aspetos importantes da ACM. O terceiro aspecto 
que merece ser ressaltado é em relação à natureza das variáveis, ou seja, nas variáveis qualitativas (ou tratadas como tal), que são traduzidas através de categorias, e que por isso também são chamadas de variáveis categorizadas ou variáveis categorias.

Dessa forma, a seleção das variáveis e indicadores que se pretende utilizar é o primeiro desafio a ser superado na ACM, pois devem traduzir da melhor forma o fenômeno a ser estudado. Essas informações constituirão uma matriz de partida, ou seja, a matriz que registra os dados da fase anterior da pesquisa, da recolha de informações, composta de $n$ indivíduos (empresas) caracterizados segundo $m$ múltiplas propriedades (variáveis). Interessa ressaltar que a abordagem relacional das múltiplas variáveis que caracterizam os indivíduos resulta na caracterização de diferentes grupos que podem ser descritos, de forma geral, a partir dos seguintes resultados esperados: a) da identificação de especificidades das associações entre as categorias das múltiplas variáveis em análise, avaliando assim o perfil de cada grupo; b) da observação do posicionamento relativo dos vários grupos, onde a análise das distâncias entre os grupos permite visualizar a existência de relações de associações ou de oposição, formando (ou fatores).

Essas informações mostram que durante o procedimento de organizar as informações qualitativas a serem utilizadas na $\mathrm{ACM}$ é preciso ter muita atenção no processo de categorização. As variáveis a serem utilizadas tem que ser as melhores possíveis para que o resultado seja coerente com a realidade a ser estudada.

Quando se possui um número muito elevado de variáveis é possível dividir as variáveis por temas, ou seja, conjunto/grupos de variáveis que refletem características distintas do objeto estudado. Ao mesmo tempo, pode-se escolher algumas dessas variáveis para fazerem parte de todas as análises, para serem fixas, ou seja, independente da característica a ser estudar pode se ter um conjunto delas que se queira manter para verificar algum tipo de associação.

A partir da organização por temas dos dados e da categorização das variáveis, as informações formarão uma matriz de input na qual se dispõem $n$ indivíduos (as 115 empresas, formando 115 linhas da matriz) que são caracterizados segundo $m$ atributos (neste caso por 122 variáveis devidamente categorizadas, uma para cada coluna da matriz), ou seja, uma matriz 115 x 122, conforme exemplifica o Quadro 1.

\begin{tabular}{|c|c|c|c|c|c|}
\hline \multirow{2}{*}{$\begin{array}{c}\text { Objetos } \\
\text { (Empresas) }\end{array}$} & \multicolumn{5}{|c|}{ Variáveis } \\
\cline { 2 - 6 } & $\mathrm{V}_{1}$ & $\mathrm{~V}_{2}$ & $\mathrm{~V}_{3}$ & $\ldots$ & $\mathrm{V}_{122}$ \\
\hline Empresa 1 & 1 & 2 & 5 & $\ldots$ & 2 \\
\hline Empresa 2 & 4 & 3 & 1 & $\ldots$ & 1 \\
\hline Empresa 3 & 2 & 1 & 2 & $\ldots$ & 1 \\
\hline$\ldots$ & $\ldots$ & $\ldots$ & $\ldots$ & $\ldots$ & $\ldots$ \\
\hline Empresa 115 & 3 & 4 & 4 & $\ldots$ & 2 \\
\hline
\end{tabular}

Quadro 1 - Exemplo de matriz de inputs utilizada na ACM Fonte: Resultados da Pesquisa. 
Cada categoria, de cada variável, está associada a um código. Esta codificação é realizada individualmente em cada variável, sempre iniciando pelo número 1 até $\mathrm{k}_{\mathrm{j}}$ (número máximo de categorias para cada variável apresenta). Inicia-se em 1 pois números inferiores não são reconhecidos como válidos para efeitos de realização de uma ACM. Outra informação importante se refere à natureza das variáveis: apesar das variáveis serem tratadas como qualitativas, não existe restrição quanto ao uso de variáveis quantitativas, desde que estas sejam categorizadas e que sejam atribuídos códigos às mesmas. Além disso, essa categorização não exige uma ordenação, pois o número atribuído a cada categoria apenas será utilizado como um identificador e não sofrerá qualquer influência no processo de transformação na qual os dados são submetidos.

No SPSS é possível selecionar somente as variáveis e os indivíduos que se deseja para a análise. Isso quer dizer que, além do fato de agregar as variáveis por temas, conforme descrito anteriormente, também é possível selecionar os objetos levando-se em consideração alguma outra característica. Por exemplo, como estão sendo analisadas empresas, podem-se escolher somente aquelas empresas do classificadas como indústrias, ou somente aquelas classificadas como de comércio/serviços. Nos resultados deste trabalho utilizar-se-á somente dos resultados das empresas do setor industrial. Mas isto não exige que se tenham duas matrizes, desde que o software que seja utilizado realize as seleções necessárias. Deve-se ressaltar também que a responsabilidade do investigador é a de organizar a matriz de input sendo que as restantes operações da ACM, que serão detalhadas a seguir, já são de responsabilidade a posteriori do próprio software.

No cálculo da $A C M$ a matriz de input será transformada em uma matriz binária $\left(G_{j}\right)$, que registra uma coluna para cada categoria $\left(k_{j}\right)$ existente numa variável. Ou seja, cada linha apresentará 1 se o indivíduo pertencer a essa categoria e 0 caso não pertença. Assim, cada linha da matriz $\mathrm{G}_{\mathrm{j}}$ terá somente um elemento 1 e elementos 0 , já que cada categoria de cada variável é mutuamente exclusiva e exaustiva. De tal modo que essa nova matriz apresentará $n$ linhas que corresponderão ao total de objetos, e tantas colunas quantos forem o total de categorias do conjunto total de variáveis sob análise.

Ainda são necessárias mais duas outras matrizes para o cálculo da ACM que sistematizam as frequências das categorias das $m$ variáveis e o número de respostas válidas em cada uma. São as matrizes $D_{j}$ e a $M_{j}$, respetivamente. $A$ matriz $D_{j}$ é uma matriz diagonal, para cada variável, cuja diagonal mostra a frequência marginal das suas $\mathrm{k}_{\mathrm{j}}$ categorias. Deste modo, para as $m$ variáveis obtém-se a matriz $\mathrm{D}_{\mathrm{j}}$ do tipo $p x p$, onde (número total de categorias em análise). A matriz $\mathrm{M}_{\mathrm{j}}$ identifica o número de respostas válidas e é definida para cada variável $j$. Também é uma matriz diagonal do tipo $n x n$ e binária: será 1 se houver ocorrência no intervalo [1; $\mathrm{k}_{\mathrm{j}}$ ] e 0 se ocorre uma não resposta. Do somatório das matrizes $M_{j}$ resulta uma matriz $M_{*}$.

O procedimento seguinte é submeter os dados qualitativos de input a um processo de 
quantificação, com o objetivo de estimar as quantificações ótimas (optimal scaling) para os parâmetros sob análise: categorias e indivíduos. Assim, cada categoria estará associada a uma quantificação e cada indivíduo a um score. Costuma-se utilizar pelo menos duas dimensões, ou seja, duas soluções para as quantificações dos dados visto que um dos potenciais usos da ACM é o de representar graficamente os espaços multidimensionais (o espaço das $p$ categorias e $n$ indivíduos) em planos.

Essas quantificações (enquanto coordenadas) permitem projetar as categorias ou os indivíduos. A representação das categorias tem por objetivo fazer a análise das associações entre as múltiplas variáveis e a dos indivíduos permite avaliar o seu posicionamento no espaço. De forma que a quantificação das categorias e os scores dos indivíduos são revestidos por determinadas propriedades interpretativas, na medida em que preservam a reciprocidade que existe entre eles. Conforme afirma Carvalho (2008, p. 42-43):

Ao nível da descodificação da informação contida na matriz de input é sabido que as
categorias representam os objetos a elas associados e, por sua vez, os objetos são
caracterizados por partilharem certas categorias. É justamente essa reciprocidade
intrínseca à matriz dos dados que as quantificações das categorias e os scores dos
objetos preservam entre si. Está implícito no processo de transformação das categorias
e dos objetivos a aplicação de um princípio matemático: princípio das médias recíprocas,
por via do qual o procedimento da ACM determina as quantificações, até ser atingida
a solução ótima. (...) Sendo a quantificação de uma categoria igual à média dos scores
de todos os objetos nela inseridos e, por sua vez, o score de cada object proporcional à
média das quantificações de todas as categorias às quais ele está associado, é possível
perceber como estas definições são subsidiárias uma da outra, no sentido em que existe
uma contribuição recíproca na sua determinação.

A quantificação das $p$ categorias das $m$ variáveis é calculada da seguinte forma:

$$
Y=D^{-1} G^{\prime} X
$$

Em que: $Y=$ Matriz de quantificação das categorias; $D=$ Matriz de frequência das p categorias; $\mathrm{G}=$ Matriz binária (assinala as presenças-ausências dos indivíduos); $\mathrm{X}=$ Matriz dos scores dos objetos.

De forma que a quantificação das categorias $(Y)$ é igual a média dos scores dos objetos que nelas se inserem (G'X), ponderada pela frequência de ocorrências (D) das categorias. Sendo:

$$
X \cong G Y / m
$$

Para que essa proporcionalidade seja transformada numa igualdade, basta subordinar-lhe um fator de proporcionalidade, nesse caso, o valor da inércia $(\lambda)$ da dimensão para o qual estão sendo determinados os scores. Ou seja:

$$
X \cong G Y / m^{1} / \lambda
$$

É possível traduzir em distâncias a relação existente entre as quantificações das categorias e entre os scores dos indivíduos. Quando os indivíduos possuem distâncias próximas (ou idênticas) também apresentarão scores próximos (ou idênticos). Essa 
proximidade cria grupos de indivíduos (tendencialmente) homogêneos, e o contrário também ocorre, se estiverem distantes os indivíduos tendem a serem diferentes quanto aos perfis estudados, quanto aos atributos. No contexto de uma análise de homogeneidade as variáveis são consideradas homogêneas quando estiverem classificadas nos mesmos grupos, os indivíduos que estão nas mesmas categorias.

E da mesma forma, assim como os indivíduos com perfis semelhantes correspondem a scores semelhantes, também as categorias que forem tendencialmente partilhadas pelos mesmos indivíduos estarão associadas quantificações semelhantes. Isso quer dizer que quando são representados graficamente os indivíduos tendem a situar-se na vizinhança das categorias mais implicadas na definição dos seus perfis, formando subgrupos.

É nesse sentido que a ACM traz um benefício muito importante, pois este método permite rever num espaço de menores dimensões, facilitando a interpretação por parte do pesquisador, a estrutura multifacetada e relacional do espaço de partida. Além disso, como existe uma representação gráfica destas informações, os eixos que são resultantes do processo matemáticos utilizados para quantificar os dados qualitativos de input, possuem uma característica estrutural. Ou seja, como cada indivíduo passa a ter associado um score que é determinado em função de todas as categorias por ele partilhadas, contemplando as $m$ variáveis que definem o perfil de cada um dos $n$ indivíduos.

Nesta perspectiva, existem alguns resultados que o software SPSS proporciona das análises ACMs que são muito úteis, sendo que serão detalhados os três que serão utilizados neste trabalho, quais sejam:

- A tabela da Discrimination Measures que mostra, por variável, a quantificação da variância após processada a quantificação ótima. Quanto maior for o valor, e quanto mais o valor de aproximar de 1, mais a variável em questão discrimina os indivíduos em análise. E também apresenta o total do '\% of Variance' para cada dimensão, ou seja, é possível comparar as dimensões entre si, ter indícios sobre a importância de cada uma.

- A tabela de quantifications para todas as categorias de todas as variáveis. Esses resultados mostram o valor de cada categoria para cada dimensão, e com isso mostra quais são as categorias mais homogêneas e que estruturam as dimensões. Assim, é possível, em conjunto com a Discrimination Measures, identificar quais as variáveis mais explicativas e, dentro delas, quais as categorias que mais influenciaram a variável.

- A tabela object scores para todos os indivíduos analisados, nesse caso, todas as empresas. Com esse resultado é possível verificar quais são as empresas que mais se associam em cada dimensão e possibilita criar um gráfico do tipo XY no próprio SPSS, onde em cada eixo estará representada uma dimensão possibilitando verificar as relações existentes entre os indicadores, ao mesmo tempo em que se clarifica a importância que cada um deles tem na estruturação do espaço em análise.

Assim, serão apresentados estes resultados das ACMs: a tabela da Discrimination Measures; a tabela de quantifications; e a tabela object score. A próxima seção apresenta 
uma breve caracterização das empresas inquiridas e os resultados das ACMs.

\section{I CARACTERIZAÇÃO DAS EMPRESAS INQUIRIDAS DE TOLEDO-PR}

Toledo é um município jovem. Foi emancipado em 1951, desmembrado de Foz do Iguaçu pela Lei $n^{\circ} 790$ de 14 de novembro de 1951 do Estado do Paraná. Tem apresentado crescimento da população total desde os anos de 1960, sendo este crescimento resultado de um aumento da população urbana em detrimento da população rural. Houve uma inversão na década de 1970, quando a população urbana ultrapassou em absoluto a população rural, conforme mostra o Gráfico 1.

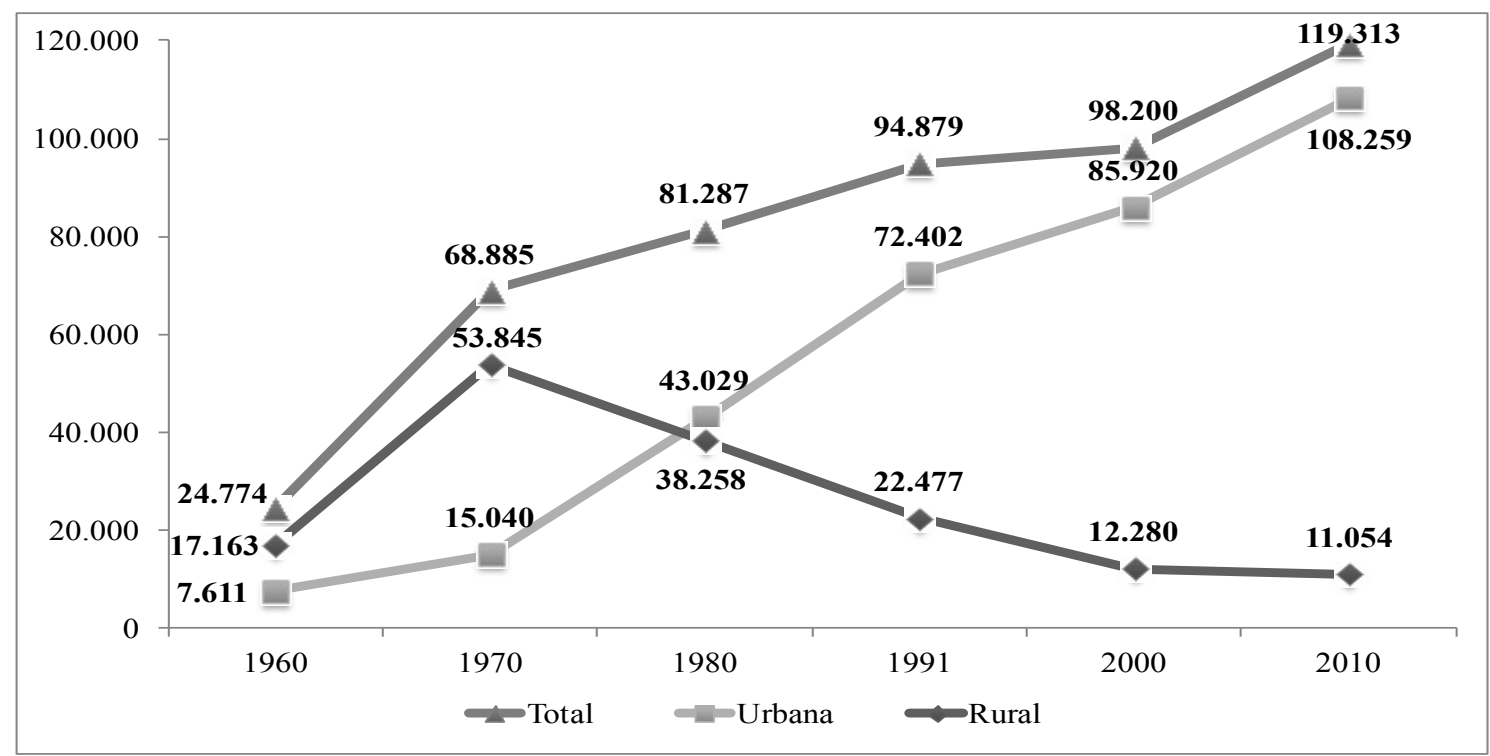

Gráfico 1 - População censitária total, urbana e rural para o município de Toledo - 1960/2010 Fonte: Elaboração do autor a partir de IPARDES (2020).

Por outro lado, quando se analisa a dinâmica do emprego percebe-se que, a despeito de uma mudança 'radical' no perfil da população rural para urbana, a participação dos setores econômicos no total do emprego municipal não se alterou na mesma intensidade. Apesar de toda a importância que o setor primário possui para o município, este setor possui a menor participação no que se refere à absorção de emprego formal. $O$ setor que mais concentra empregos é o terciário (comércio e serviços) e apresentou uma pequena redução de seu share a partir de 1990, em função do aumento da participação do setor secundário, crescimento este que foi positivo até 2010. A partir de 2010 o setor terciário reforçou a sua participação em detrimento do setor secundário. Quando se analisa os valores absolutos do emprego é o setor de serviços o que mais emprega, conforme detalha a Tabela 1. 


\begin{tabular}{c|c|c|c|c|c|c|c|c}
\hline \multirow{2}{*}{ Ano } & \multicolumn{2}{|c|}{ Indústria } & \multicolumn{2}{c|}{$\begin{array}{c}\text { Comércio e } \\
\text { Serviços }\end{array}$} & \multicolumn{2}{c|}{ Agropecuária } & \multicolumn{2}{c}{ Total } \\
\cline { 2 - 9 } & Abs. & Var.\% & Abs. & Var.\% & Abs. & Var.\% & Abs. & Var.\% \\
\hline 1985 & 4.504 & & 7.823 & & 636 & & 12.963 & \\
1990 & 5.661 & 25,7 & 9.452 & 20,8 & 145 & $-77,2$ & 15.258 & 17,7 \\
1995 & 5.854 & 3,4 & 7.869 & $-16,7$ & 941 & 549,0 & 14.664 & $-3,9$ \\
2000 & 7.988 & 36,5 & 10.792 & 37,1 & 713 & $-24,2$ & 19.493 & 32,9 \\
2005 & 13.019 & 63,0 & 16.575 & 53,6 & 1.082 & 51,8 & 30.676 & 57,4 \\
2010 & 16.503 & 26,8 & 21.411 & 29,2 & 1.080 & $-0,2$ & 38.994 & 27,1 \\
2014 & 18.060 & 9,4 & 28.178 & 31,6 & 1.176 & 8,9 & 47.414 & 21,6 \\
\hline
\end{tabular}

Tabela 1 - Emprego total e setorial, valores absolutos e variação em relação ao período anterior, Toledo $-1985 / 2014$

Fonte: Elaboração dos autores a partir de RAIS (2020).

Notas: Abs. = valores absolutos; Var.\% = variação percentual em relação ao período anterior; Com./Serv. = subsetores do comércio e serviços; Agrop. = setor da agropecuária .

Quando se analisam as variações relativas em relação aos períodos anteriores, é possível perceber que o setor industrial apresentou aumentos relativos maiores nos períodos entre 1985/1990 e 2000/2005. Nos demais períodos, a variação foi maior para o setor terciário e com valores maiores que o dobro em relação ao setor industrial a partir de 2010. Já o setor da agropecuária apresentou variações diferenciadas em todo o período. Como esse setor é maioritariamente de emprego informal essa variável não reflete o dinamismo real desse setor.

O que a Tabela 1 mostra é que estes dados não revelam a existência de uma reestruturação produtiva intersetorial no município de Toledo. Levando-se em conta que a reestruturação é o aumento do setor terciário (comerciais e de serviços) em relação aos demais setores, essa reestruturação mostra sinais positivos somente a partir de 2010 quando o setor industrial perde força na geração relativa de empregos. Quando se analisam internamente os grandes setores com maior grau de detalhamento, percebemse outros movimentos setoriais interessantes, com destaque para o setor industrial.

Conforme ressaltado por Alves e Marques da Costa (2015), o setor industrial é o setor que vem sofrendo a maior reestruturação intrassetorial. Em 2000, já se percebia que o tradicional subsetor responsável pela maior absorção de emprego - o de alimentos e bebidas - começava a perder participação. Contudo, a partir de 2000 o subsetor da indústria química passou a apresentar um crescimento mais significativo, ampliando sua participação no subsetor industrial total de forma considerável, passando de 3,9\% para $13,4 \%$, no período de 2000 a 2010, enquanto o subsetor de alimentos e bebidas diminuiu sua participação de $59,7 \%$ para $43,5 \%$. Também é preciso ressaltar o crescimento da construção civil, mecânica e de calçados. O subsetor químico é maioritariamente influenciado pela existência de uma grande indústria de produtos farmacêuticos, que cresceu muito a partir de 2000 e justifica a maior parte do crescimento deste subsetor 
no município. No caso do subsetor de alimentos e bebidas, também se deve destacar a existência de um grande estabelecimento associado ao abate de animais e preparação da carne que também apresentou crescimento no período, mas como já concentrava muito emprego no início do período, o seu crescimento relativo foi menor, justificando a perda de share para os demais subsetores.

Com isso, se percebe uma reestruturação do setor industrial do município de Toledo, ou melhor, uma diversificação industrial, onde outros subsetores crescem e ampliam as opções de emprego e, consequentemente, vão ter associados outras formas de gestão e de organização tecnológica, que respondem a práticas mais atuais.

Além disso, o Quadro 2 mostra uma mudança na hierarquia dos subsetores que mais crescem. A despeito do subsetor de alimentos e bebidas ainda ser o mais importante em relação ao número de empregados, este perdeu participação relativa, no setor industrial passando de 59,7\% em 2000 para 43,5\% em 2013. Essa diminuição ocorreu devido ao crescimento de quatro subsetores: da indústria química que passou de 3,9\% em 2000 para 19,6\% em 2013, da construção civil (de 6,9\% para 10,3\%), da indústria têxtil (11,6\% para $8,5 \%$ ), e da indústria mecânica (de $1,5 \%$ para $4,1 \%$ ).

\begin{tabular}{|c|c|c|}
\hline SETORES & 2000 & 2014 \\
\hline \multirow{17}{*}{$\begin{array}{c}\text { Setor } \\
\text { Secundário } \\
\text { (Industrial) }\end{array}$} & $\left({ }^{* * *}\right)$ & $\left({ }^{* * *}\right)$ \\
\hline & Alim. e Bebidas........ $5.122(26,3 \%, 64,1 \%)$ & Alim. e Bebidas........ 8.756 (18,5\%, 48,5\%) \\
\hline & Ind. Têxtil ............... $997(5,1 \%, 12,5 \%)$ & Ind. Química ............ 4.146 ( 8,7\%, 23,0\%) \\
\hline & Const. Civil ............... & Const. Civil ................ 2.581 ( 5,4\%, 14,3\%) \\
\hline & Madeira e Mobil....... & Ind. Têxtil ................... 1.559 ( 3,3\%, 8,6\%) \\
\hline & Ind. Química .............. & Ind. Mecânica ............ \\
\hline & Ind. Metalúrgica........ & Ind. Metalúrgica ........ \\
\hline & Prod. M. não Met..... & Bor, Fumo, Couros .. \\
\hline & Bor, Fumo, Couros .. & Ind. Calçados............ \\
\hline & Ind. Mecânica ............ & Madeira e Mobil....... $326(0,7 \%, \quad 1,8 \%)$ \\
\hline & Mat. de Transp.......... & Prod. M. não Met..... \\
\hline & Ind. Calçados............. & Elét. e Comunic. ....... \\
\hline & Papel e Gráf. ............ & Papel e Gráf. ............. \\
\hline & Elét. e Comunic........ & Ser. Ind. Uti. Púb. .... \\
\hline & Extrativa Mineral....... & Mat. de Transp.......... \\
\hline & Ser. Ind. Uti. Púb. .... & Extrativa Mineral...... \\
\hline & ....... $7.988(41,0 \%, 100 \%)$ & $\ldots 18.060(38,1 \%, 100 \%)$ \\
\hline $\begin{array}{l}\text { TOTAL DO } \\
\text { MUNICÍPIO }\end{array}$ & Total .........................19.493 (100\%, 100\%) & Total .......................... 47.414 (100\%, 100\%) \\
\hline
\end{tabular}

Quadro 2 - Número absoluto e relativo (\%) do emprego industrial formal, por subsetores, Toledo 2000/2014

Fonte: Elaboração do autor a partir de RAIS (2020)

$\left(^{\star}\right)=$ Valor absoluto, número de empregados. $\left({ }^{\star \star}\right)=$ Valor relativo, percentual em relação ao total geral do número de empregados do município de Toledo. $\left({ }^{\star \star \star}\right)=$ Valor relativo, percentual em relação ao setor industrial. 
A indústria química, com uma grande empresa empregadora, e outras empresas de menor dimensão, foi quem apresentou o maior crescimento do share (passou de 4,2\% para 23,0\% em relação ao emprego total do município no período de 2000 a 2014) e da variação de números absolutos, com um aumento 3.814 vínculos empregatícios no mesmo período.

O subsetor de alimentos e bebidas ficou em segundo lugar na variação do número absoluto do emprego, refletindo o crescimento da maior indústria existente no município, como o crescimento de outras empresas de menor dimensão tanto de alimentos como de bebidas.

Em seguida destacou-se a construção civil, amplamente aquecida a partir de 2000 devido à construção de estabelecimentos comerciais e residenciais. A vinda de empresas, os programas sociais federais de financiamento imobiliário e a especulação imobiliária no município contribuíram para o crescimento do subsetor. Por outro lado, a indústria têxtil tem se tornado cada vez mais importante, estando na sua maioria associada a empresas médias e pequenas, mesmo tendo diminuído sua participação relativa foi o quarto subsetor em termos de variação absoluta. As indústrias mecânicas e metalúrgicas acabaram acompanhando o bom desempenho dos demais subsetores e, também, foram beneficiadas pelo crescimento do agronegócio que gera uma demanda forte nesses subsetores.

É neste contexto de dinamismo do setor industrial que são apresentados os resultados da pesquisa de campo. Os resultados mostraram que todas as empresas inquiridas eram constituídas por capital privado nacional. A maioria das empresas eram micros e pequenas, conforme mostram as Tabelas 2 e 3. O segundo ponto a se destacar é que, das 115 empresas inquiridas, 18 eram do setor secundário e as demais 97 do setor terciário. Neste trabalho somente as empresas do setor industrial serão analisadas.

Verifica-se que, do total, 6 empresas do setor industrial empregavam mais de 100 pessoas (médias e grandes empresas, das atividades de alimentos e bebidas, indústria têxtil, química e outras indústrias). Destas, destacaram-se uma empresa de alimentos e bebidas (abate e processamento de carnes) e uma química (farmacêutica) com mais de mil empregados (grandes empresas) e, ainda, uma empresa com mais de 500 empregos da atividade têxtil (especificamente de fabricação de fios de algodão). Ressalta-se que utilizou-se o conceito de tamanho das empresas apresentado por SEBRAE (2015), em que as empresas industriais são consideradas microempresas quando possuem até 19 empregados, pequenas entre 20 e 99, médias entre 100 e 499, e grandes quando possuem mais de 500 . 


\begin{tabular}{|c|c|c|c|c|c|}
\hline Intensidade tecnológica e atividades & $\begin{array}{c}\text { Micro- } \\
\text { empresa }\end{array}$ & $\begin{array}{l}\text { Pequena } \\
\text { Empresa }\end{array}$ & $\begin{array}{c}\text { Média } \\
\text { Empresa }\end{array}$ & $\begin{array}{l}\text { Grande } \\
\text { Empresa }\end{array}$ & $\begin{array}{l}\text { Total } \\
\text { geral }\end{array}$ \\
\hline IBT & 3 & 2 & 3 & 2 & 10 \\
\hline Alimentos e bebidas & 1 & 1 & 1 & 1 & 4 \\
\hline Ind. Têxtil (ind. fios, confecções) & - & 1 & 1 & 1 & 3 \\
\hline Outras ind. (papelão, brinquedos, móveis) & 2 & - & 1 & - & 3 \\
\hline IMBT & - & 1 & - & - & 1 \\
\hline Outras indústrias (mármores, granitos) & - & 1 & - & - & 1 \\
\hline IMAT & 3 & 3 & - & - & 6 \\
\hline $\begin{array}{l}\text { Ind. Metal Mec./Transp. (avicultura, } \\
\text { carrocerias, piscicultura, máquinas) }\end{array}$ & 2 & 2 & - & - & 4 \\
\hline $\begin{array}{l}\text { Ind. Química (cosméticos, prod. } \\
\text { domissanitários) }\end{array}$ & 1 & 1 & - & - & 2 \\
\hline IAT & - & - & - & 1 & 1 \\
\hline Ind. Química (Farmacêutica) & - & - & - & 1 & 1 \\
\hline TOTAL SETOR INDUTRIAL & 6 & 6 & 3 & 3 & 18 \\
\hline
\end{tabular}

Tabela 2 - Número empresas industriais, por tamanho, intensidade tecnológica e atividades, a partir do número de emprego respondido pelos empresários, Toledo - 2014

Fonte: Pesquisa de campo com tratamento próprio.

Notas: IAT - Indústrias de alta tecnologia, IMAT - Indústrias de média-alta tecnologia, IMBT - Indústrias de média-baixa tecnologia, IBT - Indústrias de baixa tecnologia.

Pela Tabela 3 verifica-se o número de emprego das empresas inqueridas e percebese que o somatório do emprego representava $70,1 \%$ de todo o emprego industrial de Toledo em 2014.

\begin{tabular}{|l|r|r|r|r|r|}
\hline \multicolumn{1}{|c|}{ Intensidade tecnológica e atividades } & $\begin{array}{c}\text { Micro- } \\
\text { empresa }\end{array}$ & $\begin{array}{c}\text { Pequena } \\
\text { Empresa }\end{array}$ & $\begin{array}{c}\text { Média } \\
\text { Empresa }\end{array}$ & $\begin{array}{c}\text { Grande } \\
\text { Empresa }\end{array}$ & Total geral \\
\hline IBT & $\mathbf{2 6}$ & $\mathbf{7 2}$ & $\mathbf{5 9 0}$ & $\mathbf{7 . 5 0 0}$ & $\mathbf{8 . 1 8 8}$ \\
\hline Alimentos e bebidas & 1 & 36 & 210 & 7.000 & 7.247 \\
\hline Ind. Têxtil (ind. fios, confeç̧ões) & - & 36 & 100 & 500 & 636 \\
\hline Outras ind. (papelão, brinquedos, móveis) & 25 & - & 280 & - & 305 \\
\hline IMBT & - & $\mathbf{2 0}$ & - & - & $\mathbf{2 0}$ \\
\hline Outras indústrias (mármores, granitos) & - & 20 & - & - & 20 \\
\hline IMAT & $\mathbf{3 5}$ & $\mathbf{1 1 9}$ & - & - & $\mathbf{1 5 4}$ \\
\hline $\begin{array}{l}\text { Ind. Metal Mec./Transp. (avicultura, } \\
\text { carrocerias, piscicultura, máquinas) }\end{array}$ & 21 & 64 & - & - & 85 \\
\hline $\begin{array}{l}\text { Ind. Química (cosméticos, prod. } \\
\text { domissanitários) }\end{array}$ & 14 & 55 & - & - & 69 \\
\hline IAT & - & - & - & $\mathbf{4 . 3 0 0}$ & $\mathbf{4 . 3 0 0}$ \\
\hline Ind. Química (Farmacêutica) & - & - & - & 4.300 & 4.300 \\
\hline Total geral & $\mathbf{6 1}$ & $\mathbf{2 1 1}$ & $\mathbf{5 9 0}$ & $\mathbf{1 1 . 8 0 0}$ & $\mathbf{1 2 . 6 6 2}$ \\
\hline
\end{tabular}

Tabela 3 - Número de empregos, por tamanho, intensidade tecnológica e atividades, a partir do número de emprego atual respondido pelos empresários, Toledo - 2014

Fonte: Pesquisa de campo com tratamento próprio.

Notas: IAT - Indústrias de alta tecnologia, IMAT - Indústrias de média-alta tecnologia, IMBT - Indústrias de média-baixa tecnologia, IBT - Indústrias de baixa tecnologia. 
Quando se analisam as empresas recorrendo à classificação do EUROSTAT (2009 e 2013) que as agrega por nível de intensidade de tecnologia, é possível verificar que das três maiores empresas industriais duas são de baixa tecnologia (IBT) e uma de alta tecnologia (IAT). Os subsetores de baixa tecnologia e de média alta tecnologia (IMAT) são onde se concentram a maioria das demais empresas industriais inquiridas do município.

Também é preciso ressaltar que algumas das empresas inquiridas possuíam filiais, no município ou fora dele, outras que eram filiais e ainda aquelas que eram franquias. Havia quatro empresas que possuíam filiais: uma microempresa de fabricação de caixas de papelão, uma média da IBT de fabricação de brinquedos com filiais em Toledo e em Osasco (sendo esta última uma filial de distribuição), uma pequena da IMAT de cosméticos com filiais em Duque de Caxias (RJ) e São Paulo (SP), e uma grande da IAT, de produção de produtos farmacêuticos, sendo estas filiais de distribuição e não de produção, sendo estas localizadas, pelo menos, uma em cada Estado do Brasil com exceção dos Estados de Tocantins, Sergipe, Acre, Roraima e Amapá devido a questões relacionadas ao mercado de consumo de menor dimensão.

Outra empresa afirmou ser filial, ou seja, estabelecimento cuja empresa matriz não era localizada em Toledo. Era a maior indústria do município, a empresa de abate e processamento de carnes com a matriz no município de Chapecó-SC. Com relação aos estabelecimentos que eram franquias não houve nenhum caso encontrado no setor industrial do município.

Tendo-se detalhado como as empresas inquiridas são distribuídas por tamanhos e subsetores intensivos em tecnologia, aplicou-se uma Análises de Correspondências Múltiplas (ACM), a partir das respostas dos empresários, buscando-se, com isso, identificar características comuns a esse conjunto de empresas e que fossem mais fiéis à realidade das empresas pertencentes aos grandes setores.

As respostas dos inquéritos foram, primeiramente, categorizadas para depois serem utilizadas nas ACMs. As variáveis correspondem àquelas que se relacionam com características comuns entre elas, quando se analisa o mercado geográfico de atuação das empresas (de fornecedores, de consumidores e de vendas). Essas informações são relevantes pois destacam o grau de relações existentes entre estas empresas com outras empresas da região e de outras regiões do país e exterior.

Além destas variáveis, quatro variáveis foram selecionadas para serem utilizadas como variáveis fixas. As variáveis correspondentes a cada grupo são listadas no Quadro 3.

Com isso, a seguir são apresentados os resultados da análise de correspondências múltiplas. Para cada dimensão (ou fatores) apresentada, serão destacadas as variáveis com maior peso de discriminação da dimensão. Nos testes realizados as variáveis estiveram presentes em pelo menos uma das dimensões resultantes até às seis primeiras. Por isso, optou-se por apresentar somente as seis primeiras dimensões, pois esse número já é 
suficiente para apresentar as principais características diferenciadoras das empresas em suas diferentes características.

\begin{tabular}{|c|l|}
\hline Variáveis & \multicolumn{1}{|c|}{ Descrição das variáveis utilizadas } \\
\hline \multirow{3}{*}{ Fixas } & $\checkmark$ Tempo - Tempo de atividade (a partir do ano de fundação da empresa); \\
& $\checkmark$ Tecnologia - Nível de Tecnologia; \\
& $\checkmark$ FilialFranquia - Filiais e Franquias; \\
& $\checkmark$ Tamanho - Dimensão da empresa (segundo SEBRAE). \\
& $\checkmark$ ToledoF - Fornecedores de Toledo \\
& $\checkmark$ ParanáF - Fornecedores de outros municípios do Paraná (exclui Toledo) \\
& $\checkmark$ BrasilF - Fornecedores de outros Estados do Brasil (exclui Paraná) \\
Variáveis & $\checkmark$ Importam - Fornecedores de outros países (Importam) \\
referentes & $\checkmark$ ToledoC - Mercado consumidor de Toledo \\
ao mercado & $\checkmark$ ParanáC - Mercado consumidor de outros municípios do Paraná (exclui \\
de atuação & Toledo) \\
empresas & $\checkmark$ BrasilC - Mercado consumidor de outros Estados do Brasil (exclui Paraná) \\
industriais & $\checkmark$ Exportam - Mercado consumidor de outros países (exportam) \\
& $\checkmark$ Prod_Varejo - Produz para consumo direto/final (varejo) \\
& $\checkmark$ Prod_Atacado - Produz para atacado \\
& $\checkmark$ Prod_Sub - Produz para empresas subcontratadas \\
& $\checkmark$ Prod_Socios - Produz para as outras empresas pertencentes aos sócios \\
& $\checkmark$ Prod_Outras_ind - Produz para outra(s) unidade(s) industriais
\end{tabular}

Quadro 3 - Variáveis (medidas de discriminação) utilizadas nas análises fatoriais de correspondência múltiplas

Fonte: Pesquisa de campo com tratamento próprio.

Utilizou-se como média de corte das variáveis com maior peso de discriminação nas dimensões o valor de discriminação da própria dimensão na escolha das variáveis. Por exemplo, na Dimensão 1 do Quadro 4 o valor de discriminação total foi de 26,671\% ou 0,267 , sendo todas as variáveis maiores que 0,267 selecionadas pois são estas as que mais influenciaram no valor da dimensão total. Já para as empresas selecionadas, será utilizado como média a média simples do total de empresas, sendo a média de 0,056 (1/18 empresas). Esta metodologia de escolha é respaldada por Carvalho (2008), onde se pode encontrar maiores detalhes.

\section{I ANÁLISE DE CORRESPONDÊNCIAS MÚLTIPLAS PARA O SETOR INDUSTRIAL DE TOLEDO-PR}

Quando se analisam os mercados de atuação das empresas industriais, em relação à origem geográfica dos fornecedores de matérias-primas e em relação ao mercado consumidor, pode-se resumir, inicialmente, as informações da seguinte forma (Tabela 4 e 5). 


\begin{tabular}{|c|c|c|c|c|c|}
\hline \multirow[b]{2}{*}{$\begin{array}{c}\text { Intensidade tecnológica e } \\
\text { atividades }\end{array}$} & \multirow[b]{2}{*}{$\begin{array}{c}\text { Total de } \\
\text { empresas } \\
\text { inquiridas }\end{array}$} & \multicolumn{4}{|c|}{ Empresas (\%) que possuem o mercado fornecedor } \\
\hline & & $\begin{array}{c}\text { Fornecedores } \\
\text { de Toledo }\end{array}$ & \begin{tabular}{|} 
Forn. de \\
outros mun. do \\
Paraná
\end{tabular} & $\begin{array}{l}\text { Fornecedores } \\
\text { de outras Ufs }\end{array}$ & $\begin{array}{c}\text { Fornecedores } \\
\text { de outros } \\
\text { países }\end{array}$ \\
\hline IBT & 10 & 40,0 & 60,0 & 70,0 & 40,0 \\
\hline Alimentos e bebidas & 4 & 50,0 & 75,0 & 50,0 & 50,0 \\
\hline $\begin{array}{l}\text { Ind. Têxtil (ind. fios, } \\
\text { confeções) }\end{array}$ & 3 & - & 33,3 & 100,0 & 66,7 \\
\hline $\begin{array}{l}\text { Outras ind. (papelão, } \\
\text { brinquedos, móveis) }\end{array}$ & 3 & 66,7 & 66,7 & 66,7 & \\
\hline IMBT & 1 & - & 100,0 & 100,0 & 100,0 \\
\hline $\begin{array}{l}\text { Outras indústrias } \\
\text { (mármores, granitos) }\end{array}$ & 1 & - & 100,0 & 100,0 & 100,0 \\
\hline IMAT & 6 & 50,0 & 50,0 & 100,0 & 33,3 \\
\hline $\begin{array}{l}\text { Ind. Metal Mec./Transp. } \\
\text { (avic., carrocerias, pisc., } \\
\text { máq.) }\end{array}$ & 4 & 75,0 & 75,0 & 100,0 & 50,0 \\
\hline $\begin{array}{l}\text { Ind. Química (cosméticos, } \\
\text { prod. domissanitários) }\end{array}$ & 2 & - & - & 100,0 & \\
\hline IAT & 1 & - & - & 100,0 & 100,0 \\
\hline $\begin{array}{r}\text { Ind. Química } \\
\text { (farmacêutica) }\end{array}$ & 1 & - & - & 100,0 & 100,0 \\
\hline $\begin{array}{l}\text { Média do Setor } \\
\text { Industrial }\end{array}$ & 18 & 38,9 & 55,6 & 83,3 & 44,4 \\
\hline
\end{tabular}

Tabela 4 - Mercado fornecedor das empresas inquiridas do setor secundário, por percentual das empresas em relação ao total do respetivo mercado, por intensidade tecnológica e atividades, Toledo 2014

Fonte: Pesquisa de campo com tratamento próprio.

Nota: "-" = igual a zero. Quanto mais escuras forem as cores das células, maior é o percentual de empresas relativo ao grupo destacado ( $0,0 \%$ até $25,0 \% ; 25,1 \%$ até $50,0 \% ; 50,1 \%$ até $75,0 \% ; 75,1 \%$ até $100,0 \%)$.

O mercado fornecedor (Tabela 4) das indústrias abrange os limites municipais e tem como origens outros municípios do próprio do Paraná, do Brasil e de outros países. Interessante que quanto maior é a intensidade de tecnologia das indústrias, mais abrangente é o mercado fornecedor. Exemplos são as indústrias de alta tecnologia e as indústrias de média alta tecnologia (principalmente do subsetor químico) que possuem um mercado fornecedor nacional e internacional. Mas o fato de as empresas possuírem uma menor intensidade de tecnologia não quer dizer necessariamente que o mercado fornecedor é exclusivamente local e regional. O que se pode verificar é que essas empresas, principalmente as de baixa tecnologia de alimentos, bebidas e outras indústrias, adquirem boa parte das suas matérias-primas no município e na região enquanto as outras não o fazem, mas também possuem fornecedores de outros Estados e até de outros países, mas comparavelmente em menor proporção. 


\begin{tabular}{|c|c|c|c|c|c|}
\hline \multirow[b]{2}{*}{$\begin{array}{c}\text { Intensidade tecnológica e } \\
\text { atividades }\end{array}$} & \multirow[b]{2}{*}{$\begin{array}{l}\text { Total de } \\
\text { empresas } \\
\text { inquiridas }\end{array}$} & \multicolumn{4}{|c|}{ Empresas (\%) que possuem o mercado consumidor } \\
\hline & & $\begin{array}{l}\text { Consumidores de } \\
\text { Toledo }\end{array}$ & $\begin{array}{l}\text { Consumidores } \\
\text { de outros } \\
\text { municípios do } \\
\text { Paraná }\end{array}$ & $\begin{array}{l}\text { Consumidores } \\
\text { de outras Ufs }\end{array}$ & $\begin{array}{l}\text { Consumidores de } \\
\text { outros países }\end{array}$ \\
\hline IBT & 10 & 80,0 & 60,0 & 50,0 & 30,0 \\
\hline Alimentos e bebidas & 4 & 100,0 & 50,0 & 50,0 & 50,0 \\
\hline $\begin{array}{l}\text { Ind. Têxtil (ind. fios, } \\
\text { confeções) }\end{array}$ & 3 & 66,7 & 66,7 & 66,7 & 33,3 \\
\hline $\begin{array}{l}\text { Outras ind. (papelão, } \\
\text { brinquedos, móveis) }\end{array}$ & 3 & 66,7 & 66,7 & 33,3 & - \\
\hline IMBT & 1 & 100,0 & 100,0 & - & - \\
\hline $\begin{array}{l}\text { Outras indústrias } \\
\text { (mármores, granitos) }\end{array}$ & 1 & 100,0 & 100,0 & - & - \\
\hline IMAT & 6 & 50,0 & 66,7 & 100,0 & 16,7 \\
\hline $\begin{array}{l}\text { Ind. Metal Mec./Transp. } \\
\text { (avicultura, carrocerias, } \\
\text { piscicultura, máquinas) }\end{array}$ & 4 & 75,0 & 75,0 & 100,0 & 25,0 \\
\hline $\begin{array}{l}\text { Ind. Química } \\
\text { (cosméticos, prod. } \\
\text { domissanitários) }\end{array}$ & 2 & - & 50,0 & 100,0 & - \\
\hline IAT & 1 & 100,0 & 100,0 & 100,0 & 100,0 \\
\hline $\begin{array}{r}\text { Ind. Química } \\
\text { (farmacêutica) }\end{array}$ & 1 & 100,0 & 100,0 & 100,0 & 100,0 \\
\hline $\begin{array}{l}\text { Média do Setor } \\
\text { Industrial }\end{array}$ & 18 & 72,2 & 66,7 & 66,7 & 27,8 \\
\hline
\end{tabular}

Tabela 5 - Mercado consumidor das empresas inquiridas do setor secundário, por percentual das empresas em relação ao total do respetivo mercado, por intensidade tecnológica e atividades, Toledo 2014

Fonte: Pesquisa de campo com tratamento próprio.

Nota: "-" = igual a zero. Quanto mais escuras forem as cores das células, maior é o percentual de empresas relativo ao grupo destacado $(0,0 \%$ até $25,0 \% ; 25,1 \%$ até $50,0 \% ; 50,1 \%$ até $75,0 \% ; 75,1 \%$ até $100,0 \%)$.

O mercado consumidor (Tabela 5) das empresas inquiridas é bastante local e regional e quanto maior é a intensidade de tecnologia na qual a empresa se encontra, mais abrangente tende a ser o seu mercado de consumidores. As atividades industriais relacionadas às atividades de média baixa e de baixa tecnologia possuem, no geral, um mercado consumidor bastante local e regional. Não pode deixar de se ressaltar, entretanto, a existência de empresas com consumidores de outros Estados e de outros países, mesmo sendo dos subsetores de baixa tecnologia, como os de alimentos e bebidas. A indústria de alta tecnologia possui um mercado consumidor bastante amplo, desde o mercado local, até ao nacional e internacional. O mesmo ocorre com as indústrias de média alta tecnologia onde o mercado consumidor nacional é bastante importante.

Para se perceber se essas características estão mesmo associadas pelo tipo de subsetor ou por outras características, como a dimensão das empresas ou o destino da produção (se para o atacado, varejo, etc.), os resultados da análise de correspondências múltiplas trazem resultados relevantes. 
O Quadro 4 apresenta os resultados da análise de correspondências múltiplas em relação ao mercado de atuação das empresas industriais do município de Toledo.

\begin{tabular}{|c|c|c|c|c|c|}
\hline $\begin{array}{c}\text { Dimensão } 1 \\
(26,671 \% \text { ou } 0,267)\end{array}$ & $\begin{array}{c}\text { Dimensão } 2 \\
(18,715 \% \text { ou } 0,187)\end{array}$ & $\begin{array}{c}\text { Dimensão } 3 \\
(18,332 \% \text { ou } 0,183)\end{array}$ & $\begin{array}{c}\text { Dimensão } 4 \\
(14,293 \% \text { ou } 0,143)\end{array}$ & $\begin{array}{c}\text { Dimensão } 5 \\
(10,295 \% \text { ou } 0,103)\end{array}$ & $\begin{array}{c}\text { Dimensão } 6 \\
(10,067 \% \text { ou } 0,101)\end{array}$ \\
\hline $\begin{array}{l}\text { Tamanho das } \\
\text { empresas ................,696 } \\
\text { Produz para } \\
\text { atacado ...................,599 } \\
\text { Produz para } \\
\text { empresas } \\
\text { subcontratadas .........,584 } \\
\text { Mercado } \\
\text { consumidor de } \\
\text { outros paises } \\
\text { (exportam) ...............,551 } \\
\text { Mercado } \\
\text { consumidor de } \\
\text { outros Estados do } \\
\text { Brasil .......................,443 } \\
\text { Tempo de } \\
\text { atividade ...................,420 } \\
\text { Produz para } \\
\text { consumo } \\
\text { direto/final (varejo)....,289 }\end{array}$ & $\begin{array}{l}\text { Tamanho das } \\
\text { empresas................., } 831 \\
\text { Tempo de } \\
\text { atividade ..................., 550 } \\
\text { Produz para } \\
\text { outra(s) unidade(s) } \\
\text { industriais ................, 520 } \\
\text { Fornecedores de } \\
\text { outros Estados do } \\
\text { Brasil......................., } 295 \\
\text { Filiais e Franquias ....., 249 } \\
\text { Fornecedores de } \\
\text { Toledo......................., } 214 \\
\end{array}$ & \begin{tabular}{|l|} 
Mercado \\
consumidor de \\
Toledo ..................... ,644 \\
Fornecedores de \\
outros municipios \\
do Paraná ................ ,530 \\
Filiais e Franquias.... ,348 \\
Fornecedores de \\
outros Estados do \\
Brasil ....................... 253 \\
Fornecedores de \\
Toledo ......................,246 \\
Nivel de \\
Tecnologia ................,190 \\
Produz para \\
empresas \\
subcontratadas .........,183
\end{tabular} & $\begin{array}{l}\text { Produz para as } \\
\text { outras empresas } \\
\text { pertencentes aos } \\
\text { sócios......................,720 } \\
\text { Tempo de } \\
\text { atividade ..................,394 } \\
\text { Nivel de } \\
\text { Tecnologia ................,370 }\end{array}$ & $\begin{array}{l}\text { Fornecedores de } \\
\text { outros países } \\
\text { (Importam) ................,383 } \\
\text { Filiais e Franquias ...., } 347 \\
\text { Produz para } \\
\text { consumo } \\
\text { direto/final (varejo) ....,267 } \\
\text { Mercado } \\
\text { consumidor de } \\
\text { Toledo......................,164 } \\
\text { Mercado } \\
\text { consumidor de } \\
\text { outros Estados do } \\
\text { Brasil.........................,157 } \\
\text { Tempo de } \\
\text { atividade ....................,137 }\end{array}$ & $\begin{array}{l}\text { Tempo de } \\
\text { atividade...................,465 } \\
\text { Filiais e Franquias....,432 } \\
\text { Tamanho das } \\
\text { empresas ..................,407 } \\
\text { Mercado } \\
\text { consumidor de } \\
\text { outros municipios } \\
\text { do Paraná.................,142 }\end{array}$ \\
\hline Empresas D1 $\geq 0,056$ & Empresas D2 $\geq 0,056$ & Empresas D3 $\geq 0,056$ & Empresas D4 $\geq 0,056$ & Empresas D5 $\geq 0,056$ & Empresas D6 $\geq 0,056$ \\
\hline $\begin{array}{l}\text { IAT, G3...................., } 196 \\
\text { IBT, M4 ....................., } 183 \\
\text { IBT, m5 ....................., } 165 \\
\text { IBT, m1 ...................., } 128 \\
\text { IBT, M1 ...................., } 125\end{array}$ & 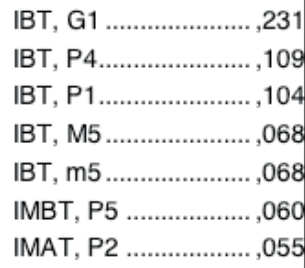 & 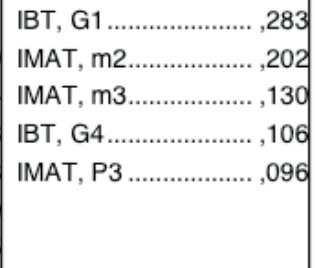 & $\begin{array}{l}\text { IMAT, m2 ................., } 680 \\
\text { IBT, m5 .....................,058 } \\
\text { IMAT, P2 ..................,056 }\end{array}$ & 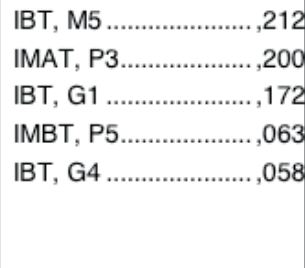 & 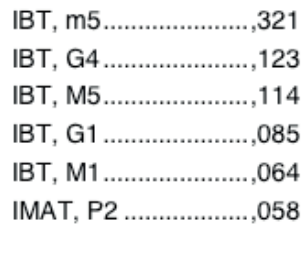 \\
\hline
\end{tabular}

Quadro 4 - Análise fatorial de correspondências múltiplas para o setor industrial de Toledo: quantificação das categorias, por Dimensão para o Grupo Mercados - 2014

Fonte: Pesquisa de campo com tratamento próprio.

Notas: $\mathrm{m}$ - microempresa, P - Pequena empresa, M - média empresa, G - Grande empresa, 1 - Alimentos e Bebidas; 2 - Ind. Mecânica e Transporte; 3 - Ind. Química; 4 - Ind. Têxtil; 5 - Outras Ind; IAT - Indústrias de alta tecnologia; IMAT Indústrias de média-alta tecnologia; IMBT - Indústrias de média-baixa tecnologia; IBT - Indústrias de baixa tecnologia.

A variável que mais explica os tipos de mercados existentes das empresas industriais é a variável tamanho, o que é comprovado pela variável de maior peso de discriminação nas duas primeiras dimensões. O que essas duas dimensões reforçam é a influência que o tamanho das empresas possui quando se analisam os seus mercados de atuação. Esses resultados mostram associações entre variáveis que reforçam alguns argumentos que são tradicionalmente mencionados quando se analisam empresas por tamanhos ou subsetores de atuação. Algumas destas argumentações costumam enfatizar o tamanho da empresa com relação ao mercado consumidor dos mesmos. Por exemplo, é comum a associação entre grandes empresas e a exportação, ou as micro e pequenas empresas e a produção para um mercado mais local e regional. Essas duas primeiras dimensões resultantes ajudam a esclarecer se estas associações clássicas se verificam em Toledo ou não.

No caso da Dimensão 1 existe uma discriminação bastante relevante da variável de 
produção para atacados e, com valores bastante próximos, da produção para empresas subcontratadas e que exportam. Mas também existe nessa dimensão uma influência das variáveis relacionadas a um mercado consumidor de nível nacional, o tempo de atividade e da produção para o consumidor final (varejo). Quando se analisam as empresas que possuem maior participação na discriminação desta dimensão percebe-se que são aquelas de grande e média dimensão, dos subsetores de média alta e de alta tecnologia. Produzem para atacados pois não têm como principal característica o fato de produzirem para o consumidor final, são exportadoras, e também produzem para empresas subcontratadas. A principal empresa dessa dimensão é a empresa farmacêutica, e a segunda a empresa de fabricação de fios e filamentos. Ambas são empresas antigas no município e não possuem relação direta com a produção primária municipal. As demais, e que influenciaram com menor intensidade, são empresas dos subsetores de baixa tecnologia, de produção de móveis e de alimentos e bebidas. São empresas mais recentes que as duas primeiras, com mercado de consumo mais local, com exceção da última, de média dimensão e de produção de bebidas, que também produz para atacados e para empresas subcontratadas, e que exporta, o que mostra a existência de uma maioria de empresas com maior tamanho na Dimensão 1 o que corrobora com a afirmação anterior de que as maiores empresas possuem mercados mais abrangentes.

Na Dimensão 2 o que é mais relevante é a existência de três variáveis fixas sendo duas delas as mais importantes nesse grupo, a variável tamanho das empresas e a variável tempo de atividade. Além dessas duas variáveis, uma terceira, a de filiais e franquias, reforça o peso que essas variáveis possuem na formação dessa dimensão e na configuração das empresas de Toledo. Aqui, a empresa que é mais ressaltada é a grande empresa de alimentos com o maior peso nessa dimensão. Essa empresa, que é uma filial de um dos maiores gigantes do mercado alimentício mundial, é a maior empregadora individual do setor industrial do município, uma das mais antigas em tempo de funcionamento com mais de 21 anos de existência, e uma das empresas com capacidade de utilizar grande escala de matéria-prima local (produção de aves, suínos e milho, principalmente). Essa é a única empresa que adquire suas matérias-primas principais exclusivamente no município e na região (e também a única desta dimensão que é exportadora). As outras todas possuem um mercado fornecedor mais abrangente, do local ao nível nacional. Assim, essa dimensão é seguida por empresas de baixa e de média baixa tecnologia, micro, pequenas e médias, de alimentos, têxteis e outras indústrias (fabricação de brinquedos, fabricação de caixas de papelão e fabricação de produtos do mármore e granitos). As duas primeiras possuem filiais e, por isso, ajudam a ressaltar essa variável da dimensão. A última empresa desta dimensão, da indústria de média alta tecnologia (IMAT), do subsetor da indústria mecânica e transporte, possui um valor muito próximo ao valor médio da dimensão, e partilha de todas as características mencionadas anteriormente em relação ao mercado fornecedor de matérias-primas local e nacional. 
As demais dimensões resultantes não ressaltam a variável tamanho das empresas como sendo a variável que mais discrimina. Por exemplo, na Dimensão 3 são ressaltadas as variáveis referentes ao mercado de atuação mais local, em relação ao mercado consumidor e ao fornecimento de matéria-prima. Nesse último aspeto, também se encontram mercados de fornecimento regionais e nacionais. O que mais sobressai nessa dimensão, mais uma vez, é a grande empresa produtora de alimentos que também ficou em primeiro lugar na Dimensão 2. A particularidade desta empresa, na Dimensão 3, é a de ser a única com mercado de consumo e de matérias-primas local e de produzir para outras empresas subcontratadas. Todas as demais desta dimensão possuem um mercado de fornecimento de matéria-prima e de consumo nacionais, e possuem uma relação oposta à empresa anterior e por isso ficaram na mesma dimensão. São empresas que produzem máquinas, produtos domissanitários, fios de algodão e cosméticos. Pelo fato de ser um mix de IMAT e de IBT, a variável nível de tecnologia também foi ressaltada nessa dimensão.

A Dimensão 4 apresenta a particularidade de possuir como variável mais discriminativa a produção para outras empresas pertencentes aos sócios. Mais duas variáveis são destacadas, com menos poder de discriminação, o tempo de atividade e o nível de tecnologia. A microempresa da indústria mecânica e transporte (IMAT de produção de tanques e equipamentos para a piscicultura) foi a única empresa industrial que afirmou produzir para outras empresas pertencentes aos sócios e por isso obteve maior valor nessa dimensão. As outras duas empresas, de produção de móveis (IBT) e de fabricação de máquinas e equipamentos para avicultura (IMAT), possuem (juntamente com a primeira) um mercado de consumo e de fornecimento de matérias-primas mais local e regional. As duas IMAT são importadoras, e a primeira é exportadora, ressaltando a competitividade das microempresas do município.

Outra forma de ilustrar a distribuição dessas empresas em relação aos mercados é representar um conjunto de dimensões num gráfico. Com isso é possível visualizar como as empresas se distribuem no "espaço" das variáveis utilizadas. Utilizou-se nessa representação a Dimensão 1 , devido ao maior valor de discriminação apresentado, e a Dimensão 3. Como a segunda dimensão possui a mesma variável que a primeira dimensão como sendo a mais representativa, e como a terceira dimensão evidencia as características do mercado mais local, e também por ter um valor total muito próximo em relação à segunda, optou-se por utilizar a terceira dimensão associada à primeira nessa representação, obtendo-se um resultado mais fiel à realidade local. Neste sentido, o Gráfico 2 apresenta os resultados do cruzamento das Dimensões 1 e 3.

A associação das duas dimensões (Dimensões 1 e 3 ) reforça os aspetos que foram ressaltados na descrição do Quadro 4 anteriormente. É possível verificar que nos quadrantes A e D estão aquelas empresas que utilizam menos fornecimento de matériasprimas locais (Dimensão 3), que não possuem uma ligação muito forte com a principal 
base econômica do município que é a agropecuária. Foram os casos das empresas de produção de produtos farmacêuticos, papel, fios e brinquedos. Estas quatro empresas (do quadrante A) no conjunto representam 40,9\% do total do emprego do setor industrial em relação ao total das empresas inquiridas, o que mostra que boa parte do emprego está associado com empresas que não possuem relação direta com a matéria-prima produzida localmente. Nos quadrantes B e C estão aquelas que, ao contrário, utilizam mais insumos produzidos localmente. Nesse aspeto se destaca a grande indústria de alimentos com o maior valor (com sinal negativo) da Dimensão 3.

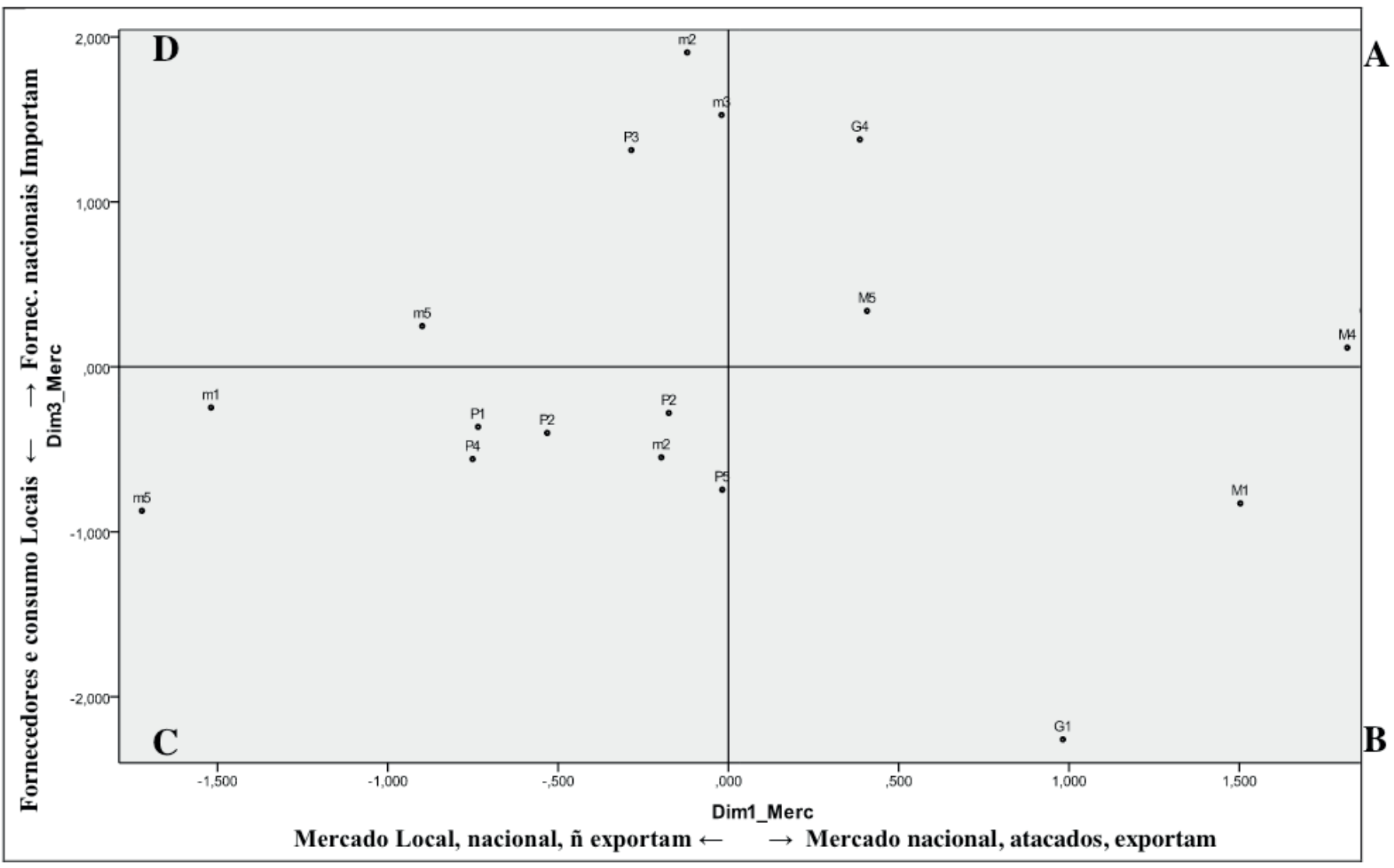

Gráfico 2 - Cruzamento dos object scores das dimensões 1 e 3, da ACM para o setor industrial de Toledo - 2014

Fonte: Resultados da Pesquisa de Campo, Tratamento próprio.

Notas: $\mathrm{m}$ - microempresa, P - Pequena empresa, M - média empresa, G - Grande empresa, 1 - Alimentos e Bebidas; 2 Ind. Mecânica e Transporte; 3 - Ind. Química; 4 - Ind. Têxtil; 5 - Outras Ind.

Por outro lado, as empresas que estão localizadas na parte direita (quadrantes A e B) também são aquelas com mercado de atuação mais abrangente e aqui se destacam as empresas de maior dimensão, médias e grandes. O contrário se visualiza do lado esquerdo do gráfico, de micros e pequenas empresas, principalmente no quadrante $\mathrm{C}$, que são aquelas empresas com mercado de atuação (consumo e fornecedores) mais local e que se utilizam de insumos também (mas não necessariamente somente) locais. São as empresas de alimentos, confecções, máquinas e implementos para a agricultura 
e piscicultura, e mármores.

\section{I CONSIDERAÇÕES FINAIS}

O objetivo deste trabalho foi analisar o mercado de atuação das empresas industriais do município de Toledo-PR em suas diversas características pelo método de Análise de Correspondências Múltiplas.

Os resultados mostraram que o setor industrial tem sido o principal responsável pela dinâmica econômica municipal desde a década de 1980 através da consolidada cadeia produtiva agroindustrial. O município fortaleceu-se no subsetor de baixa tecnologia (alimentos e bebidas), e apresentou um crescimento expressivo no subsetor de alta tecnologia (química e farmacêutica), e aqui é que o município mostra sinais de sua reestruturação na medida em que aumenta a participação de subsetores não tradicionais localmente, como o de alta tecnologia.

Quando se analisam os mercados de oferta, percebe-se que, a despeito de ser formado, em sua grande maioria, por micro e pequenas empresas, essas empresas não se comportam de forma tradicional, ou seja, micro e pequenas para atender apenas ao mercado local e médias e grandes ao mercado nacional e internacional.

Por outro lado, a análise de correspondências múltiplas mostrou os diversos tipos de empresas existentes no município. Não se pode inferir uma relação direta entre tamanho das empresas e mercados de consumo e de aquisição de matérias-primas. Existem casos de empresas de menor porte que importam ou que exportam mercadorias, o que mostra a competitividade existente entre os diferentes tamanhos de empresas.

Outra característica do setor industrial se refere àquelas empresas que não possuem uma relação direta com a produção de matérias-primas existente no município e que precisam buscar essa matéria-prima em outras regiões e até em outros países. Empresas que tem apresentado crescimento, como é o caso da farmacêutica e a de bebidas, possuem estas características e reforçam a necessidade de se incentivar a produção local destas matérias-primas para ampliar os seus reflexos no processo de desenvolvimento socioeconômico local.

Percebeu-se também que a dinâmica do município é assentada em setores com grandes empresas industriais tradicionais que se verticalizam cada vez mais, e um número cada vez maior de empresas de menor dimensão, mais flexíveis e cada vez mais internacionalizadas. Desta forma, todos estes resultados mostram que a metodologia utilizada é capaz de revelar diversas características da região a ser analisada, desde que se tenha uma matriz de informações demasiadamente bem estruturada para uso. 


\section{REFERÊNCIAS}

ALVES, Lucir Reinaldo. Reestruturação produtiva e desenvolvimento local: o caso do município de Toledo, Estado do Paraná, Brasil. 2016. 497 p. Tese (Doutorado em Geografia, especialidade em Planejamento Regional e Urbano) - Instituto de Geografia e Ordenamento do Território, Universidade de Lisboa, 2016. Disponível em <hdl.handle.net/10451/23630>

ALVES, Lucir Reinaldo; MARQUES DA COSTA, Eduarda. A reestruturação produtiva do município de Toledo (Paraná-Brasil) e o crescimento dos setores de alta tecnologia e conhecimento. In: X Congresso da Geografia Portuguesa - Os Valores da Geografia, 2015, Lisboa, Portugal. Anais..., 2015.

CARVALHO, Helena. Análise multivariada de dados qualitativos - utilização da ACM com o SPSS. Lisboa: Edições Sílabo, Lda, 2008.

COSTA, José Silva; DENTINHO, Tomaz Ponce; NIJKAMP, Peter (Coord.). Compêndio de Economia Regional - volume II - métodos e técnicas de análise regional. Princípia: Cascais, 2011.

EUROSTAT. Science, technology and innovation in Europe. Luxembourg: Office for Official Publications of the European Communities (Eurostat Pocketbooks). 2013. Disponível em: <https://goo.gl/PMm8MU> Acesso em: abr. 2020.

EUROSTAT. Science, technology and innovation in Europe. Luxembourg: Office for Official Publications of the European Communities (Eurostat Statistical books). 2009. Disponível em: <https://goo.gl/5VgtRS > Acesso em: abr. 2020.

GONÇALVES JUNIOR, Carlos Alberto. et al. Análise diferencial-estrutural e fatorial do emprego nas microrregiões paranaenses entre 2005 a 2009. In: IX Encontro Nacional da Associação Brasileira de Estudos Regionais E Urbanos (ENABER), Anais..., 2011, Natal-RN.

IBGE - Instituto Brasileiro de Geografia e Estatística. Geociências. 2017. Disponível em: <https://www.ibge. gov.br/geociencias/downloads-geociencias.html> Acesso em: abr. 2020.

IPARDES - Instituto Paranaense de Desenvolvimento Econômico e Social. Base de Dados do Estado (BDEweb). Disponível em <http://www.ipardes.gov.br/imp/index.php> Acesso em: abr. 2020.

RAIS - Relação Anual de Informações Sociais. Acesso on line às bases estatísticas da RAIS. Disponível em <http://bi.mte.gov.br/bgcaged/login.php>. Acesso em: abr. 2020.

SEBRAE - SERVIÇO BRASILEIRO DE APOIO ÀS MICRO E PEQUENAS EMPRESAS (Org.). Anuário do trabalho na micro e pequena empresa: 2014. 7 ed. Brasília, DF; DIEESE. 2015. Disponível em <https://goo. gl/YLWWuu>. Acesso em: abr. 2020. 
Abertura econômica $62,64,67,78,79,83,84$

Agroecologia 38, 39, 40, 41, 42, 43, 44, 45, 46, 47, 48, 132, 138

Análise Fatorial 17, 21, 23, 24, 108, 124

B

Baía do Sol 1, 2, 3, 7, 8, 9, 10, 11, 13, 15

Brasil 5, 6, 9, 12, 13, 16, 18, 20, 21, 30, 33, 34, 35, 36, 37, 38, 39, 40, 41, 42, 43, 44, 45, 46, 47, $48,49,50,51,52,61,63,64,65,67,69,86,107,109,120,122,129,131,133,134,139,160$, $177,178,182,187,188,189,190,191$

C

Campesinato $38,41,48$

Capital Intelectual 149, 152, 154, 160

CO2 191, 192, 195, 196, 197, 198, 199, 200, 201, 202

Comunidade $1,2,3,5,6,7,8,9,10,11,13,14,15,22,26,29,33,34,35,38,39,45,46,53$

Concórdia do Pará 17, 18, 22, 26, 36

Conhecimento $8,44,58,64,65,109,129,149,150,151,152,153,154,156,158,159,160,161$

Covid19 162, 163, 164, 171, 174, 175

Crise 45, 104, 162, 164, 167, 168, 169, 170, 171, 174, 183, 184, 201

D

Desempenho 21, 27, 36, 55, 57, 118, 130, 134, 135, 140, 141, 142, 143, 153, 154, 155, 157, 203 Desenvolvimento $1,2,3,4,5,6,7,8,9,15,16,19,20,26,27,28,29,31,33,34,35,36,40,41$, $43,44,46,47,48,50,52,53,54,58,62,63,64,86,87,88,89,104,107,108,109,128,129,132$, 138, 142, 144, 147, 149, 150, 153, 154, 155, 157, 159, 160, 161, 180, 203

Dinheiro 5, 11, 13, 41, 164, 165, 166, 167, 172, 173, 176, 185

Discriminação salarial $62,78,84$

$E$

Economia Solidária 1, 2, 3, 4, 5, 6, 9, 10, 11, 14, 15, 16, 19, 34, 37, 38, 39, 40, 41, 42, 44, 45, 46, 47,48

Educação Emancipatória 38, 39, 42, 44

Empreendimento 17, 19, 23, 28, 29, 31, 32, 33, 34, 36

Empresa 4, 43, 44, 51, 53, 54, 55, 56, 58, 61, 93, 96, 110, 111, 118, 119, 120, 123, 124, 125, 126, $127,129,142,152,153,155,157,159,160,164,170,171$ 
Energy 191, 192, 194, 195, 201, 202

Especialização 86, 88, 89, 90, 91, 93, 95, 96, 97, 98, 99, 103, 104, 203

Ethanol 191, 192, 193, 194, 195, 196, 197, 199, 200, 201, 202

\section{$\mathbf{F}$}

Fluxo de caixa 130, 135, 137

Fortaleza 1, 2, 5, 9, 12, 36

G

Gestão participativa 17, 33, 34, 144

H

Hegemonia 177, 178, 179, 180, 181, 182, 187, 188, 189, 190

I

Indústria $43,50,53,54,55,56,57,58,70,71,72,73,74,75,76,79,81,83,84,89,92,93,94$, $95,96,97,98,100,101,102,103,104,109,116,117,118,120,123,125,126,127,132,138$, 160, 201, 202

$\mathbf{L}$

Leite $31,36,130,132,133,134,135,136,137,138,139$

Liderança 50, 51, 52, 57, 59, 140, 141, 142, 143, 144, 145, 146, 147, 154

Localização 23, 70, 86, 89, 90, 91, 97, 98, 100, 101, 103, 104, 110

M

Margens 54, 130, 135, 136

Mercado 3, 4, 5, 6, 18, 19, 20, 21, 22, 27, 28, 29, 32, 33, 34, 41, 43, 49, 50, 51, 52, 54, 55, 59, $65,66,67,69,83,89,104,107,108,109,120,121,122,123,124,125,126,127,128,132,133$, $134,138,140,141,151,152,154,156,165,166,183,184,186,187$

Moeda $1,3,16$

Motivação 140, 141, 142, 143, 144, 145, 146, 147, 148, 154, 156, 157, 158

MST 38, 39, 40, 41, 45, 46, 47, 48

Mulheres 40, 41, 49, 50, 51, 52, 56, 57, 58, 59, 60, 63, 64, 68, 71, 78, 79, 80, 82, 84

Município 17, 22, 25, 26, 36, 70, 88, 90, 91, 92, 93, 95, 96, 97, 98, 99, 102, 103, 104, 107, 108, $109,110,115,116,117,118,120,122,124,125,126,127,128,129$

$\mathbf{N}$

Neoliberalismo 177, 182, 186, 187 
Organização $5,6,9,17,18,19,21,25,26,27,28,29,30,32,33,34,35,36,38,39,40,41,42$, $43,45,50,53,57,61,111,117,139,141,143,144,145,146,149,150,151,152,153,154,155$, $156,157,159,160,181$

\section{$\mathbf{P}$}

Pandemia 165, 166, 167, 168, 172, 173, 174

Pará 1, 2, 3, 10, 17, 18, 20, 21, 22, 26, 29, 34, 35, 36

Paraná 62, 70, 72, 75, 81, 83, 84, 86, 87, 88, 96, 104, 105, 106, 107, 109, 115, 122, 123, 129

Portugal 107, 129, 162, 163, 164, 167, 168, 169, 171, 173, 174

Produção Orgânica 130, 131, 132, 133, 134, 135, 137, 138, 139

Propriedade 4, 25, 30, 38, 40, 41, 43, 44, 130, 133, 134, 135, 136, 137, 152, 153, 203

$\mathbf{R}$

Raça $49,50,60,62,64,65,67,70,74,76,78,81,83$

Resultados Organizacionais $140,141,146,147$

Revolução Industrial 49, 50, 51, 53, 54, 55, 58, 59, 155, 156

S

Salário 57, 62, 65, 66, 67, 69, 71, 72, 73, 74, 75, 76, 77, 78, 79, 80, 81, 82, 83, 84, 85

Satisfação 11, 15, 17, 19, 23, 24, 25, 26, 28, 29, 30, 32, 33, 34, 36, 38, 39, 145, 146, 153

Setor Industrial $65,96,103,107,108,112,116,117,118,120,121,122,123,124,125,127,128$, 154

Sexo $62,64,65,67,69,70,71,72,73,74,76,78,79,80,82,83,109$

Sistema Financeiro $177,178,181,182,184,186,187,189,190$

Sociedade $3,4,5,9,34,35,38,40,42,46,66,70,130,131,149,150,151,153,154,160,161$, $174,179,186,203$

Sugarcane 191, 192, 193, 194, 195, 200, 201, 202

\section{T}

Toledo 86, 87, 88, 89, 90, 91, 92, 93, 95, 96, 97, 98, 99, 100, 101, 102, 103, 104, 105, 106, 107, $108,109,110,115,116,117,119,120,121,122,123,124,125,127,128,129$

Trabalhador $41,45,55,58,69,70,71,76,78,145,154,157$

Trabalho 4, 5, 8, 10, 15, 17, 18, 19, 20, 30, 31, 32, 36, 37, 38, 39, 40, 41, 42, 43, 44, 45, 46, 49, $50,51,52,55,56,57,58,59,61,63,65,66,67,69,83,85,86,87,98,104,107,109,112,114$, $118,128,129,130,133,134,137,138,140,141,143,144,145,146,147,151,154,155,156$ $157,158,160,161,162,164,165,166,168,169,170,178,180,181,184,188,191$ 


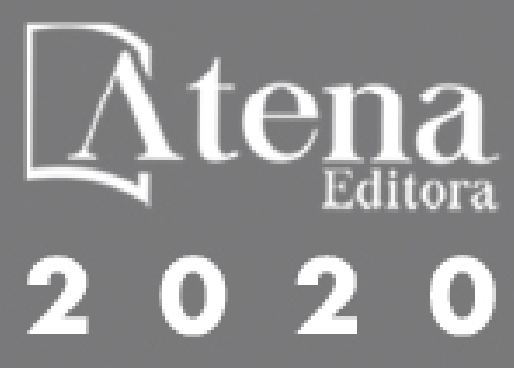

